LA-UR-94-3399

Los Alamos National Laboratory is operated by the University of California for the United States Department of Energy under contract W-7405-ENG-36.

\title{
TITLE: DEVELOPMENT OF METHODS FOR EVALUATING OPTIONS FOR IMPROVING THE AIR QUALITY IN SANTIAGO, CHILE AND ITS ENVIRONS
}

AUTHOR(S): MICHAEL D. WILLIAMS \& MICHAEL J. BROWN

SUBMITTED TO: INTERNAL REPORT

By acceptance of this article, the publisher recognized that the U S Government retains a nonexclusive, royalty-free license to publish or reproduce

the published form of this contribution or to allow others to do so for U S Government purposes.

The Los Alamos National Laboratory requests that the publisher identify this article as work performed under the auspices of the U S Department of Energy. 


\section{ADEPT \\ 1994 Draft Final Report: Summary}

Project Title: Development of Methods for Evaluating Options for Improving the Air Quality in Santiago, Chile and its Environs.

Principal Investigator: Michael D. Williams

Activities/Milestones:

1. Obtained meteorological, topological, emission, and air quality data information.

2. Simulated mesoscale meteorology and air pollution dispersion simulated in the vicinity of the Paipote and Ventanas smelters.

3. Performed sensitivity studies on the meteorological and air dispersion models in both regions of interest.

4. Delivered improved models and sample input and output data to Chilean colleagues.

5. Prepared a formal briefing for the project.

Other Activities: Travel

A trip to Santiago was made and discussion were held with our Chilean counterparts and potential sponsors. 


\title{
DRAFT FINAL REPORT - 1994 \\ Development of Methods for Evaluating Options for Improving the Air Quality in Santiago, Chile and its Environs
}

\author{
Michael D. Williams and Michael J. Brown \\ Energy and Environmental Assessment \\ Los Alamos National Laboratory
}

October 1994

\section{A. INTRODUCTION}

Officials from both the Santiago metropolitan air quality commission (La Comisión Especial de Descontaminación de le Región Metropolitana) and a government-owned copper development company (La Empresa Nacional de Minería (ENAMI)) have asked our assistance to deal with the air quality problems in Santiago and associated with smelter emissions. Due to limited funding in our second year of work, we have concentrated our efforts on further examination of two smelter sites in order to provide assistance to ENAMI.

One smelter, Ventanas, is located on the Pacific coast to the northwest of Santiago, while the other, Paipote, is located several hundred kilometers to the north. The Ventanas emissions may potentially affect Santiago air quality. As we outlined in our 1993 Final Report, several advantages of working with the smelters in the early phases of the project are: (1) the meteorological and air quality monitoring in the vicinity of the smelters allows for model validation; (2) the development of a useful emission inventory is easier, (3) the smelters pose a simpler problem, which when resolved, will provide an early benefit to our Chilean colleagues, and (4) we gain important experience as we prepare to delve deeper into Santiago's air pollution problems.

Our goals for this phase of the project include:

- determining the smelters impact on air quality in surrounding communities;

- evaluating whether air pollution from the smelters reaches Santiago; and

- helping Chilean scientists meet a national decree to have air quality models for smelters.

\section{B. MODEL DESCRIPTION}

Frequently, air quality modeling relies on simplistic assumptions about the winds and trans- 
port parameters. For example, in some simple situations a wind measured at a single site will be taken as representative of the winds throughout the region of interest. If the terrain is complex, however, such simple assumptions are of little use. In complex terrain, measurements are frequently representative of only very small volumes surrounding the site of the measurement. Air motion is greatly affected by major topographical features, which in Chile include the Pacific Ocean, the coastal range, and the Andes. The topography and a paucity of measured data in Chile pose a significant challenge to air quality modelers.

Scientists at Los Alamos National Laboratory have developed a modeling approach for complex terrain which uses a meteorological model (HOTMAC) to compute three-dimensional time-dependent wind, temperature, and water vapor fields. The output from the meteorological code is then used to drive a random particle dispersion code (RAPTAD). The intent of the approach is to represent the important physics in detail using conservation equations, rather than relying on a dense system of measurements alone.

HOTMAC is a three-dimensional time-dependent mesoscale meteorological model developed by Yamada (1985). It uses the hydrostatic approximation and a terrain-following coordinate system. HOTMAC solves conservation relations for the horizontal wind components, potential temperature, moisture, turbulent kinetic energy, and the turbulence length scale. HOTMAC describes advection, Coriolis effects, turbulent transfer of heat, momentum, and moisture. It also includes solar and terrestrial radiation effects, turbulent history effects, and drag and radiation effects of forest canopies. The development of the equations is described by Yamada (1981) and Mellor and Yamada (1982). The lower boundary conditions are defined by a surface energy balance and similarity theory. The soil heat flux is obtained by solving a heat conduction equation in the soil which ignores lateral heat transfer.

Recently some deficiencies were found in the radiation budget produced by HOTMAC. These deficiencies have been corrected and the improved model was used in this year's work. We have done a sensitivity test which resulted in noticeable changes in the surface radiation budget and the temperature and relative humidity fields, but no changes in the wind fields.

RAPTAD is a Monte-Carlo dispersion and transport code, developed by Yamada (1988). Pseudo-particles are transported with instantaneous velocities that include the mean wind field and the turbulent velocities. The turbulent velocity is randomly generated with a Gaussian distribution and standard deviation equal to that of the wind at the particle location. The location of each pseudo-particle represents the center of mass of a concentration distribution for each puff. The total concentration at any point is obtained by adding the concentration contributions of each puff at that point (a kernel method). The Monte Carlo kernel method requires that a functional form for the puff concentration distribution be chosen and that parameters that describe the width, breadth, and depth of the distribution be calculated. The approach used here is to assume a Gaussian distribu- 
tion where variances are determined from the time integration of the velocity variances encountered over the history of the puff. The variances are estimated based on the random force theory of turbulent diffusion (Lee and Stone, 1982).

The system has many advantages for applications involving complex terrain. The use of a higher-order turbulence model means that there are three-dimensional time-dependent wind fields and turbulence fields available for the representation of dispersion and transport. Transport can be treated in more detail because important terrain influences are represented in both the mean fields and the turbulence fields. The RAPTAD model works well in situations where the wind directions change with height, whereas normal Gaussian puff models are inadequate. Other random particle codes which calculate concentrations by counting random particles in cells have significant deficiencies. If the cell size is too small for the number of particles released, the computed concentrations will be very noisy (some cells will have no particles, while other cells may have one or two particles resulting in very large concentrations). If the cells are too large, the concentrations will be smeared out in an unrealistic fashion. The kernel system as used by RAPTAD avoids this problem because the pollution associated with a particle is not concentrated at a point but extends over a volume surrounding a point. The volume around the point is calculated based on the turbulence history of the particle.

In the course of running many cases with the model, we found some cases where small numerical errors led to negative values being assigned to variables such as the standard deviation of the vertical component of the wind. In very rare cases, these errors lead to an overestimate of the dilution of the pseudo-particles. In some cases, the overestimation was so severe that the model failed to give any results at all. The problem was easily remedied and the model is now more robust than it was.

\section{DATA SOURCES}

Two resolutions of topographical data were used for modeling purposes. In the vicinity of each smelter, finer scale information has been extracted from topographical maps to support modeling efforts. A US Army database with elevation contours at 1000 foot intervals was used to provide topography on a larger scale. This data set is too coarse to rely upon in the immediate vicinity of the sources, however, it has been used to represent the effects of larger scale features.

For the purposes of this work, large-scale domains on the order of 200 to 300 kilometers $(\mathrm{km})$ were needed to properly represent the major terrain influences (e.g., the Pacific Ocean and the crest of the Andes). In the case of the Ventanas site, the region was made large enough to include Santiago and an area south of Santiago which has another smelter of potential significance. In the vicinity of the smelters high resolution was required. For each site we combined the local terrain with the larger-scale terrain and constructed three computational grids. In the case of Pai- 
pote, the gridded domain had an outer mesh size of $9 \mathrm{~km}$, an intermediate mesh size of $3 \mathrm{~km}$, and an innermost mesh size of $1 \mathrm{~km}$. In the case of Ventanas, the mesh sizes were $18 \mathrm{~km}, 6 \mathrm{~km}$, and $2 \mathrm{~km}$.

We obtained and analyzed meteorological data from Quinteros which is the closest upperair meteorological station to both Santiago and the Ventanas smelter. This data was bought from the National Climatic Data Center in Asheville. We also bought data for Antofagasta, a site in the north of the country. Unfortunately, the data from the north of the country proved to be too sparse to be useful. Figure C1 displays a map of Chile with the locations of Quinteros, Santiago, Paipote, and Antofagasta. At the Paipote site we also had meteorological data from a tower on a small hill near the smelter and air quality measurements from four sites nearby.

\section{MODEL APPLICATION}

The summer months were chosen for the Ventanas simulations in order to help support the field experiments which took place in December, 1993 at the Ventanas site (note: as of this time, this data has not been made available to us). At Paipote we selected July 7, 1992, a day which had high $\mathrm{SO}_{2}$ concentrations at a key monitoring site in the little agricultural community of Tierra Amarilla. At the Paipote site, stack top and fugitive emissions of $\mathrm{SO}_{2}$ were modeled, while at Ventanas only stack top emissions were modeled.

In both cases, the model is first run with very light winds near the surface and typical upperlevel winds. This step is necessary to obtain the local wind corrections which are then subtracted from the measured low-level wind (average wind in lowest 500 meters) to obtain the large-scale driving winds. Model nudging towards the large-scale driving winds is done in order to account for synoptic-scale forces. Measured winds are then included at whatever time intervals are available. In the case of Paipote, hourly measured winds were available, but the upper-level winds were only available at intervals of 12 hours. Interpolated upper-level winds were used with the hourly tower measurements.

At both the Paipote and Ventanas sites, we used the upper-air soundings from Quinteros to estimate the initial temperature, wind speed, and relative humidity profiles. Unfortunately, the Quinteros soundings usually reported wind data at very few heights so that the 500 meter averages represented, at best, crude approximations. At the Paipote site, there was hourly data available from each of three towers, but the towers were short so that the local winds were averaged over smaller depths. In one case the tower data was treated as though it was representative of 250 meters while another run was done with a different tower which was taken as representative of only a depth of 20 meters. 


\section{E. MODEL RESULTS - PAIPOTE}

The major focus of this year's simulations at Paipote was to remedy some of the deficiencies noted in last year's work and to provide a better understanding of the model sensitivities. One of the first steps was to make some adjustments in the width of the valley. The contour map shows that the actual width of the valley bottom is about $1.5-1.6 \mathrm{~km}$. With a $1 \mathrm{~km}$ resolution, last year's model runs were made using a valley width of $1.0 \mathrm{~km}$. For this year's work, we chose a value of $2.0 \mathrm{~km}$ and thus adjusted the input data accordingly.

In last year's modeling we had modeled significant concentrations at the agricultural town of Tierra Amarilla, but the concentrations were much lower than the measured ones. We identified two major areas of uncertainty in the modeling: (1) the upper-level winds and (2) the local wind input. The upper-level winds were from Quinteros which is a considerable distance from the area of interest. We had hoped to use winds from a northern station and interpolate to the area of interest, but there were insufficient winds available at the northern site. In order to show the effect of uncertainties posed by the use of only the distant Quinteros upper-level winds, we have varied the wind aloft in this year's model simulations. We have also tested the effect of using measurements from a nearby meteorological tower for local wind input. The tower is 20 meters high and sits upon a 50 meter hill. For purposes of local wind input, we have assumed that it is representative of the lower 250 meters. In last year's work, we assumed that a much smaller tower was representative of the lowest 500 meters. In this year's work, we redid last year's simulations using the low-level tower, but assumed it was representative of only the lowest 20 meters.

As a first step to a better understanding of the problem, we have plotted the particle trajectories for last year's simulations. The upper-level wind directions from Quinteros ranged from 335 to 350 degrees. Figure E1 reports the particle positions for 9 am on July 7, 1992, while figure E2 reports the particle positions at $10 \mathrm{am}$. The hours of 9 and 10 am were chosen to depict the conditions which occur when the plume from the stack is first mixed to the ground as the morning inversion lifts. The yellow X gives the stack location, while the town of Tierra Amarilla (T) is south of the stack near the bottom of the figure. We have had an occasion to visit the site during an episode and we found that the high concentrations tended to occur when the plume drifted up the valley towards Tierra Amarilla. The pattern shown in figures E1 and E2 is significantly different than those we observed at the site.

Figure E3 shows the simulated dispersion at 9 am using the revised HOTMAC code and input from the $20 \mathrm{~m}$ high meteorological tower. Figure E4 shows the simulated dispersion for 10 am. In both cases the plume drifts too much to the east. Next, we repeated the above simulations, but instead used upper-level winds from the north. Figures E5 and E6 show the resulting dispersion for the hours of 9 and 10 am, respectively. These patterns appear much more realistic, so that the winds from the north were chosen for the remainder of the simulations. 
We now ponder on the appropriate local wind data that we should use to drive the model. Our primary concern are the winds in the vicinity of Tierra Amarilla. There are three monitors which might help in this regard: the 20 meter meteorological tower near the smelter located on top of a local hill; a 10 meter tower at Paipote; and a 10 meter tower at Tierra Amarilla. In order to determine the best tower for our model simulation, we must consider that the towers yield point measurements, whereas the modeled winds represent a one kilometer horizontal average. The 20 meter high met-tower falls between two model grid nodes and the small hills are not described with the existing grid resolution, so that the most appropriate way to use the met-tower information is not altogether clear. The Paipote tower is near the grid nodes, but it is close to a slope where the winds are likely to be changing rapidly with distance and thus the tower might not be representative of averaged winds over the model grid cell. The Tierra Amarilla tower is nearer the grid cell center and it is in the valley away from the side walls, hence the wind measurements obtained from this tower will be used in the model simulation.

Figures E7 and E8 report the null-wind dispersion simulations for 9 am and 10 am, respectively, in which the model is run with no local driving winds. The resulting plume impacts Tierra Amarilla, but the estimated concentrations for Tierra Amarilla were about the same as the 1993 simulations. The simulations did point to one interesting aspect: the winds at about 50 meters above the ground vary in the horizontal and with time much more than those at 500 meters above the ground. This situation could produce higher concentrations at Tierra Amarilla for pollutants emitted at 500 meters than those emitted at 50 meters, because the 50 meter plume is much more likely to be diverted away from Tierra Amarilla by local slope flows.

Using the null-wind simulations, the modeled values at Tierra Amarilla were averaged over the lowest 20 meters and were used as the local wind corrections. Then, the Tierra Amarilla measured winds were used to drive the model. Figures E9 and E10 report the model-measurement comparisons for the null-wind case and the Tierra Amarilla wind case, respectively. Figures E11 and E12 show the corresponding comparisons for the wind directions. The wind speeds showed very similar behavior between the null-wind and Tierra Amarilla wind cases. However, in the Tierra Amarilla case, wind directions were much different than those of the null-wind case. The agreement in the Tierra Amarilla case was much better for all stations, although the -180 to 180 degree plotting makes the improvement appear less obvious for station P.

Figures E13 and E14 show the simulated dispersion with the Tierra Amarilla winds for 9 and $10 \mathrm{am}$, respectively. The earlier plume tracks up the valley toward Tierra Amarilla in a realistic fashion, but the 10 am plume drifts rapidly off to the west. Figures E15 and E16 show the model-SO2 measurement comparisons for the 1993 case and the Tierra Amarilla case respectively. Generally, the Tierra Amarilla case shows much better agreement for the Tierra Amarilla station. However, it does show a rapid drop-off in concentrations after 10 am. 
There are four areas worthy of further investigation: the role of (1) plume-rise, (2) irrigated crops, (3) changes in the upper-level winds with time, and (4) the method of local winds interpolation. The plume heights seem to be less than those observed near the site. As we noted earlier, plumes that stabilize at a higher elevation are more likely to have dispersed less by the time they reach Tierra Amarilla and less likely to have been diverted away from Tierra Amarilla, so that higher concentrations would be produced at Tierra Amarilla over a longer time period. Much of the valley bottom is irrigated cropland. Irrigated cropland will change the local energy budget because the presence of water slows surface cooling in the evening and slows surface heating in the morning. When we used the upper-level winds from the north, we held them constant over time. Some changes in the upper-level winds are likely, but we currently have little data to address the question. One possible improvement in the local wind estimation would be to interpolate within calculated wind fields to measurement sites rather than using the nearest grid point.

\section{F. MODEL RESULTS - VENTANAS}

\section{HOTMAC and RAPTAD Sensitivity Tests}

As part of the second phase of the Chile Air Quality Program, we tested the sensitivity of the HOTMAC and RAPTAD model output to variations in the prescribed wind direction. As mentioned earlier, we are interested in determining the impact of prevailing wind direction on plume transport. Furthermore, these tests will help us evaluate the importance of the uncertainties inherent in rawinsonde wind measurements.

a) Problem set-up. Model simulations were run with five different prevailing wind directions: $180,225,270,315$, and 360 degrees. The upper boundary condition for the wind speed was set to $1.6 \mathrm{~m} / \mathrm{s}$, a value that represents typical summertime conditions. The winds were nudged towards hypothetical "rawinsonde measurements" made at Quinteros, a city relatively close to the Ventanas site. The "rawinsonde" wind speed profile was divided into three sections: 1) below $500 \mathrm{~m}$, wind speed equals $0.1 \mathrm{~m} / \mathrm{s}$; 2) from 500 to $2000 \mathrm{~m}$, wind speed linearly increases with height to $0.9 \mathrm{~m} / \mathrm{s}$; and 3) from 2000 to $4000 \mathrm{~m}$, wind speed linearly increases to $1.6 \mathrm{~m} / \mathrm{s}$.

Other boundary and initial conditions were estimated using typical summertime values: the ocean temperature and the initial land temperature were set to $15^{\circ} \mathrm{C}$; the potential temperature lapse rate was specified as $+.0075^{\circ} \mathrm{C} / \mathrm{m}$ below $1000 \mathrm{~m},+.003{ }^{\circ} \mathrm{C} / \mathrm{m}$ from 1000 to $1500 \mathrm{~m},+.006$ ${ }^{\circ} \mathrm{C} / \mathrm{m}$ from 1500 to $3000 \mathrm{~m}$, and $+.002{ }^{\circ} \mathrm{C} / \mathrm{m}$ above; and the relative humidity was assigned a value of 0.70 at the surface and decreased to 0.10 at the top of the domain. The input parameters were assumed to be invariant in the horizontal direction.

All simulations were started on Dec. 11 (Julian day 346) at 8:00 am local standard time (1st) and ended on Dec. 13 at 10 pm. The simulations were performed on a double-nested mesh surrounding the Ventanas smelter. The location, number of grids, and grid resolution for the three 
mesh types are given in Table F1. Fifteen grids extended from the surface to $4000 \mathrm{~m}$ above the

Table F1: Horizontal grid parameters

\begin{tabular}{|c|c|c|c|c|}
\hline mesh type & $\begin{array}{c}\text { SW corner } \\
(\mathbf{u t m}, \mathbf{k m})\end{array}$ & $\begin{array}{c}\text { grid size } \\
\mathbf{( k m )}\end{array}$ & no. of grids & no. of grids \\
\hline coarse & 209,6189 & 18 & 10 & N-S dir. \\
\hline medium & 245,6297 & 6 & 15 & 21 \\
\hline fine & 263,6351 & 2 & 12 & 18 \\
\hline
\end{tabular}

surface. We have included the ocean and the Andes mountains in our modeling domain in order to account for the mesoscale features of the flow. The fine mesh allows for smaller-scale features to be resolved in the vicinity of the Ventanas smelter.

The Ventanas stack parameters are described in Table F2. For the purpose of simulation, we have combined the two elevated stacks at Ventanas into one combined source by assuming that the mass and volume flow rates and the buoyancy flux were additive quantities. Plume rise ranged

Table F2: Stack parameters

\begin{tabular}{|c|c|c|c|}
\hline parameter & stack \#1 & stack \#2 & combined stack \\
\hline stack height $(\mathrm{m})$ & 155 & 155 & 155 \\
\hline stack diameter $(\mathrm{m})$ & 2 & 3 & 3.4 \\
\hline temperature $(\mathrm{K})$ & 530 & 545 & 537.9 \\
\hline vertical velocity $(\mathrm{m} / \mathrm{s})$ & 6 & 3 & 4.4 \\
\hline source strength $(\mathrm{g} / \mathrm{s})$ & 2395 & 1551 & 3946 \\
\hline
\end{tabular}

from $150 \mathrm{~m}$ at night to $400 \mathrm{~m}$ during the day. We have not included the fugitive emissions in the present simulation. The vertical and horizontal Lagrangian timescales were set to 20 and 10,000 $\mathrm{s}$, respectively.

b) Meteorological simulations. Horizontal wind vector fields computed at a ten meter height on the intermediate grid are presented in figs. F1 and F2. The inner nested grid is shown as a yellow rectangle. The Ventanas and Quinteros sites are denoted by the letters X and Q, respectively. The terrain contours are at $600 \mathrm{~m}$ intervals.

Figure F1 depicts the $2 \mathrm{pm}$ wind fields produced using a prevailing wind direction of 180 and 
360 degrees. In both cases, the winds are predominately directed up the mountain slopes, a result of the rising buoyant motion induced by the warmer land surface. When comparing the two cases, few differences can be discerned in the magnitudes and directions of the wind vectors. As an aside, the relatively low wind speeds found over the ocean are a concern, as it is expected that wind speeds would be higher there due to lower surface drag. It may be that the local wind correction scheme combined with the crude averaging of the measured winds in the 0-500 $\mathrm{m}$ layer are responsible for the low values.

Figure F2 illustrates the typical night time flow pattern at a ten meter height for a prevailing wind direction of 270 degrees. The winds are small. Nocturnal drainage flow, however, has not developed. The radiative cooling of the land surface apparently is not strong enough to overcome the strong daytime upslope flow. Only one vector field is shown in this figure, since differences cannot be discerned when using different prevailing wind directions.

In order to see more detail, we plot wind speed and wind direction versus time at the Ventanas site in fig. F3. The upper graph reveals that near-surface wind speeds are similar for different prevailing wind directions. The lower graph, however, shows that wind directions can vary up to thirty degrees. The largest differences occur, however, when the wind speeds are smallest.

Figure F4 depicts wind speeds and wind directions 429 meters above the Ventanas site. Here, we can see that wind speeds and wind directions are vastly different for the three prevailing wind direction cases of 180, 270, and 360 degrees. This result is of extreme importance to pollution transport, as plume rise will result in air pollution being lifted to this height. In the lower graph, we see that the largest difference in wind directions occur at night and that values are nearly equal to the prevailing wind direction. This result stems from the fact that the boundary-layer height is small at night (several hundred meters), thus disconnecting the flow above from surface processes. Daytime wind directions converge towards a value between 100 to 120 degrees. Recalling that the wind direction near the ground is about 290 degrees (fig. F3), we see evidence of a sea-breeze circulation. Wind speeds are smallest when the prevailing wind direction is 270 degrees because this is in the opposite direction of the upper-level sea-breeze winds.

Figure F5 illustrates the afternoon sea-breeze phenomenon. We have plotted the vector fields at heights of 10 and $428 \mathrm{~m}$ that result for a prevailing wind direction of 270 degrees. At 10 meters, strong onshore flow exists on the western half of the intermediate domain. At 428 meters, however, the winds west of $281 \mathrm{~km}$ utm are weak and offshore. Since the Ventanas site is near the coast, air pollution transport can be either to the west or to the east depending on the stack height, the magnitude of plume rise, and the amount of vertical mixing. In the next section, we will see how plumes from the Ventanas smelter interact with the changing meteorological conditions.

c) Dispersion simulations. Simulations of plume transport and dispersion using the RAPTAD model have been accomplished by incorporating meteorological input parameters (wind, turbulence, and temperature fields) obtained from the HOTMAC simulations described in the previous section. Dispersion simulations were begun thirteen hours after the meteorological simulations were started (9:00 pm lst on Dec. 11) in order to remove HOTMAC "spin-up" effects. Figures F6 
through F10 show snapshots of particle positions at different times during a forty-eight hour simulation. The black dots represent the center of the pollutant parcels. The size and height of each parcel are not depicted. In most cases, we compare the plume trajectories for the cases of prevailing wind direction equal to 180 and 360 degrees. Note: for accurate concentration computations a larger number of parcels must be released per unit time.

Seven hours after the start of the plume simulation (fig. F6), the pollutants have traveled over fifty kilometers to the east due to the westerly winds. The plume is very narrow, evidence of the lack of turbulence mixing present in night time stable environments. When the prevailing wind direction is 180 degrees, the plume travels slightly to the north and impacts on the coastal range mountain peak. When the prevailing wind direction is 360 degrees, the plume travels slightly to the south through the coastal range pass.

At 11:00 am, we see a very interesting feature: the plume is narrow between the source and about $281 \mathrm{~km}$ east-utm, and then to the east the plume suddenly expands in width (fig. F7). This most likely results from the elevated plume impinging upon the land-surface boundary layer, which is growing in height with time of day and distance from the coast.

By afternoon, evidence of the sea-breeze effect is apparent (fig. F8). For a prevailing wind direction of 180 degrees, the plume has spread out laterally and some of the pollution even extends over the ocean. When the prevailing wind is 360 degrees, a cloud of pollution travels slowly to the west, but very little reaches the ocean. In both cases, the near-stack plume travels to the west, indicating that the plume rise is large (recall from fig. F3 that the surface-level winds are from the west and the elevated winds are from the east). Figure F9 shows that the plume does not get captured in the sea-breeze circulation when the prevailing wind direction is 270 degrees.

By evening, the winds have become predominately onshore and the air pollution that was caught in the sea-breeze circulation is advected inland (fig. F10). When comparing the prevailing wind direction of 180 and 360 degrees, it is seen that the pollutant parcels are located to the north of the Ventanas site in the former case and to the south in the latter case. Clearly, the prevailing wind direction has had a large effect on the transport of the Ventanas air pollution. This result underscores the need for accurate input of synoptic-scale winds into mesoscale-type meteorological models.

\section{G. SUMMARY}

We have presented model computations of air flow and pollution dispersion in the vicinity of the Paipote and Ventanas smelters using the HOTMAC and RAPTAD models. A sensitivity analysis was performed in which the prevailing wind direction was varied. The effect on modeled wind fields and air pollution transport was discussed in detail.

In the Paipote simulation, we found that nudging towards upper-level northerly winds and the Tierra Amarilla surface-level winds greatly improved the representation of dispersion and wind patterns. We also surmised that the concentrations at Tierra Amarilla might be increased if plume rise was higher because the upper-level winds are less variable and thus more likely to transport the material to Tierra Amarilla for a longer period of time. 
In the Ventanas simulation, we found that surface-level winds were not very sensitive to prevailing wind direction changes of 180 degrees. However, daytime winds at plume centerline height (approximately $400 \mathrm{~m}$ ) were significantly affected by the prevailing wind direction. We compared plume transport for the cases of prevailing wind direction equal to 180 and 360 degrees. In both cases, the local-scale flow patterns dominated the plume transport. For most of the night and part of the day, strong onshore flow advected the plume inland. However, for a southerly prevailing wind the plume was transported slightly to the north and for a northerly prevailing wind the plume was transported to the south. We found significant plume growth resulted from plume impingement on the developing boundary layer and plume entrapment in the sea-breeze circulation (however, when the prevailing wind direction was 270 degrees, the plume did not get caught in the sea-breeze circulation). After nearly a day of plume simulation, large differences were found in pollutant parcel location as a result of the different prevailing wind directions.

In conclusion, the major accomplishments in the second phase of the Chile Air Quality Project include:

1) the processing of meteorological, topological, emission, and air quality data for use in the HOTMAC and RAPTAD models;

2) a sensitivity analysis of the HOTMAC and RAPTAD models to prevailing wind direction;

3) a successful simulation of the mesoscale flow features (e.g., sea and mountain breezes):

4) further analysis of several important local-scale meteorological and air pollution dispersion features (e.g., sensitivity of wind direction to valley topography and location of input winds at Paipote); and

5) a delivery of modified models, sample input, and sample output data to our Chilean colleagues.

Acknowledgments. We wish to thank Mr. Rick Bradley and the US Department of Energy for their support of this project. The help of Luis Matamala of CIMM (Centro de Investigación Minería y Metalurgica) and Juan Scheib L., José Sanhueza R., and Alejandro Diez of ENAMI was critical to the success of the project. In addition, Mr. Javier Vergara Fisher of the Comisión Especial de Descontaminación was also very helpful. At Los Alamos National Laboratory, Mr. Jorge Roman provided key assistance with topographical databases.

\section{REFERENCES}

Lee, J. T., and G. L. Stone, 1982, “The Use of Eulerian Initial Conditions in a Lagrangian Model of Turbulent Diffusion”, Los Alamos National Laboratory, LA-UR-82-3034, Los Alamos, NM.

Mellor, G. I. and T. Yamada, 1982, "Development of a Turbulence Closure Model for Geophysical Fluid Problems", Rev.Geophys. Space Phys., vol 20, pp 851-875. 
Yamada, T., 1981, “A Numerical Simulation of Nocturnal Drainage Flow”, J. Meteor. Soc., Japan, vol 59, pp 108-122.

Yamada, T., 1985, "Numerical Simulation of the Night 2 Data of the 1980 ASCOT Experiments in the California Geysers Area”, Archives for Meteorology, Geophysics, and Bioclimatology, Ser. A34, pp 223-247.

Yamada, T. and S. Bunker, 1988, "Development of a Nested Grid, Second Moment Turbulence Closure Model and Application to the 1982 ASCOT Brush Creek Data Simulation”, J. Appl. Meteor., vol 27, pp 562-578. 


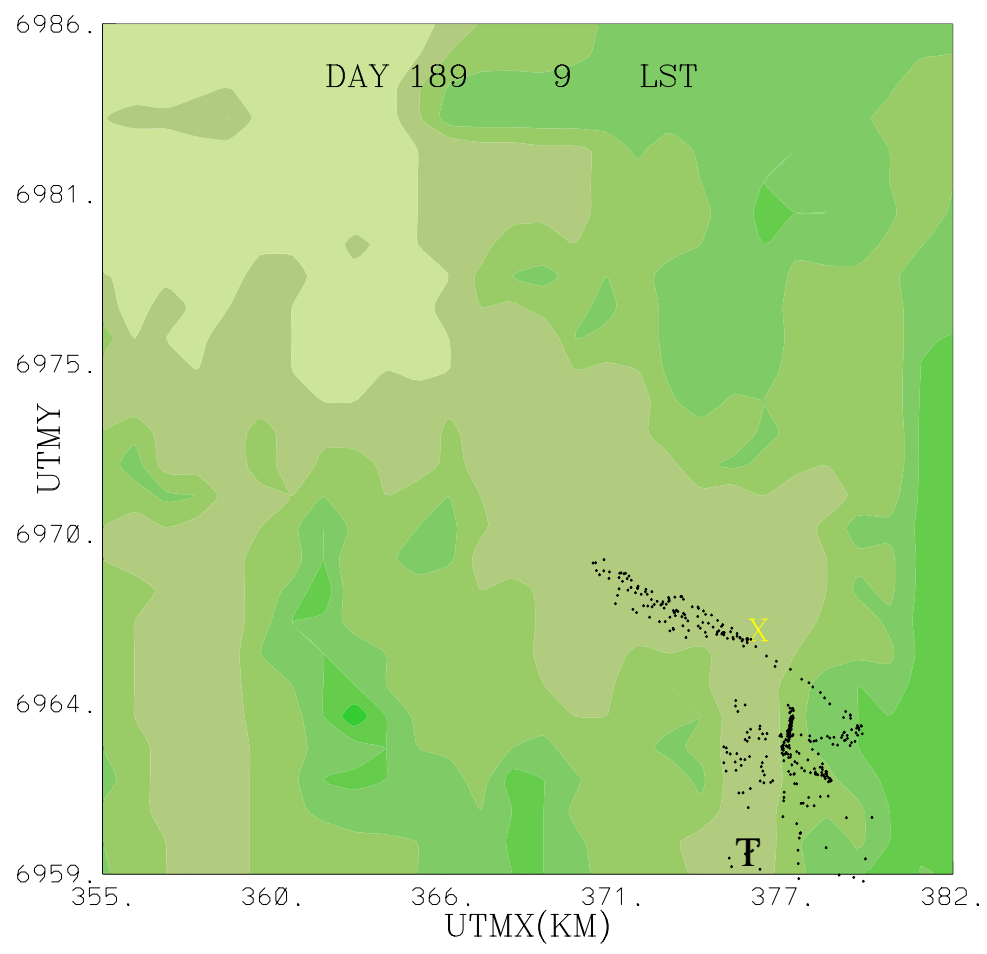

Figure E1. Simulated dispersion with input and models from the 1993 final report.

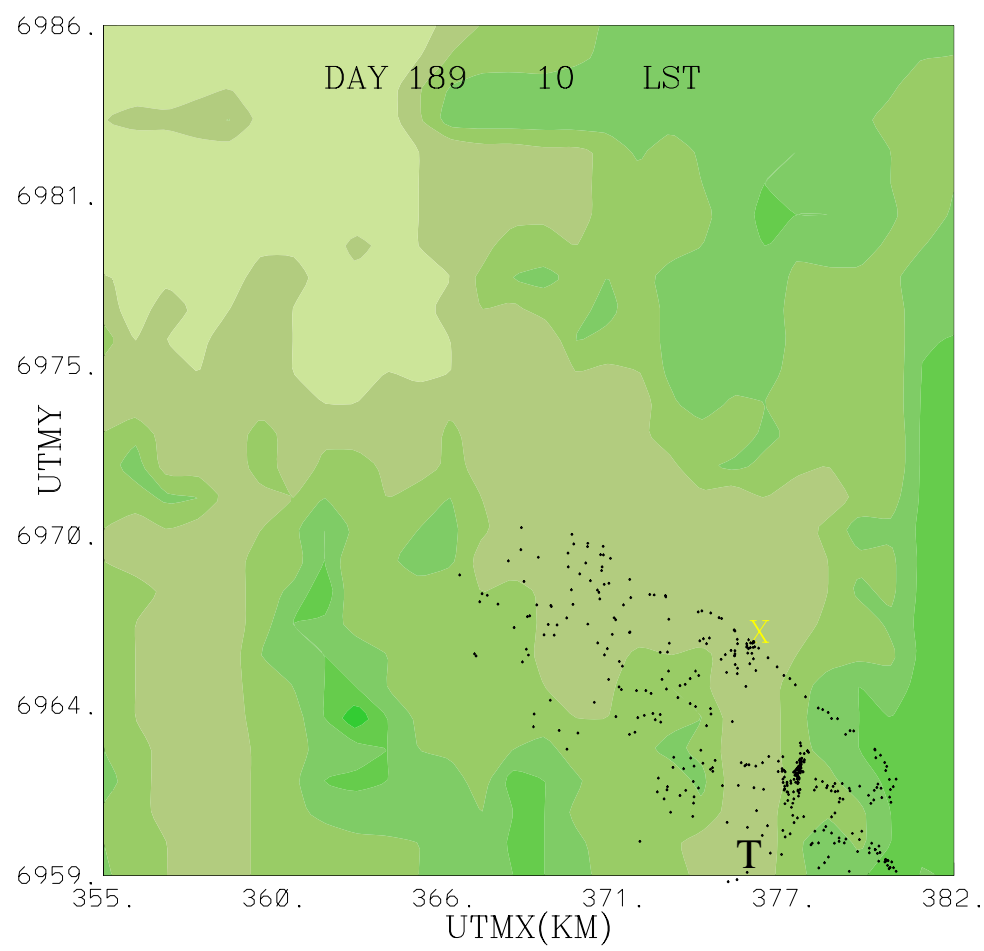

Figure E2. Simulated dispersion for 10 am with input and models from the 1993 final report. 


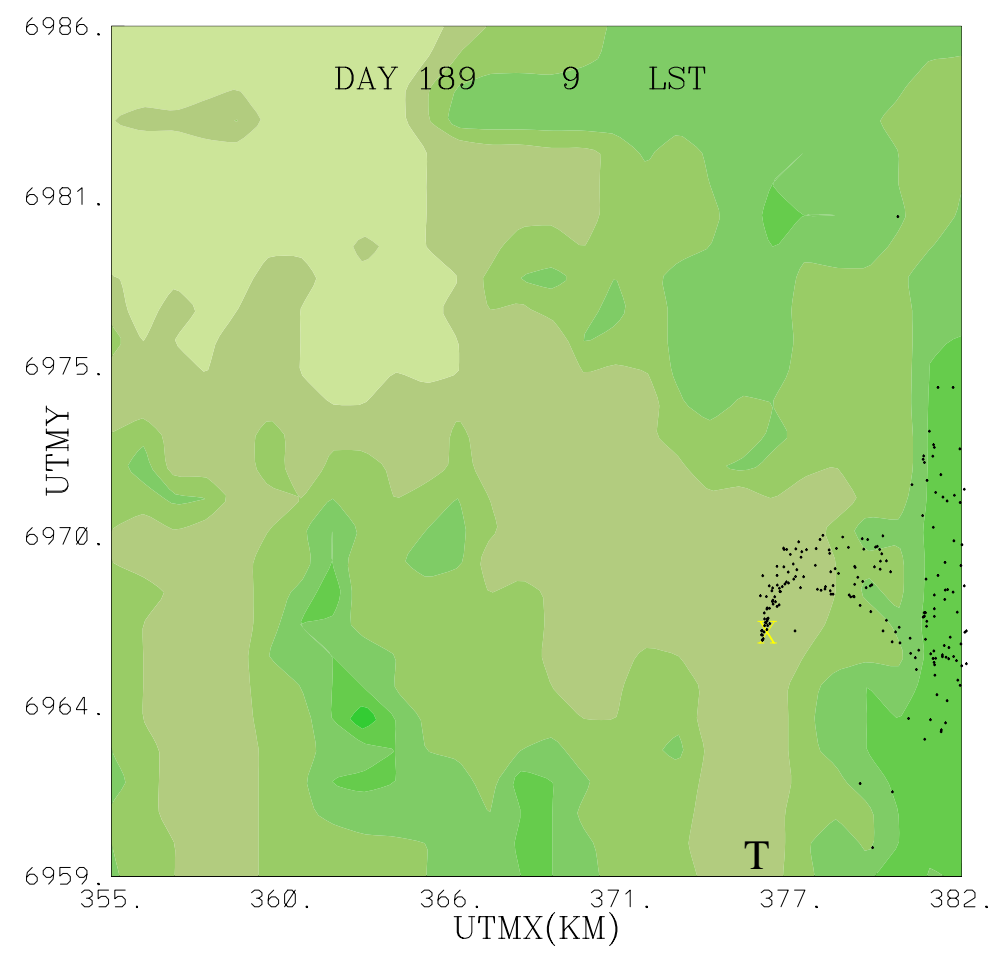

Figure E3. Simulated dispersion with the meteorological tower input and revised codes.

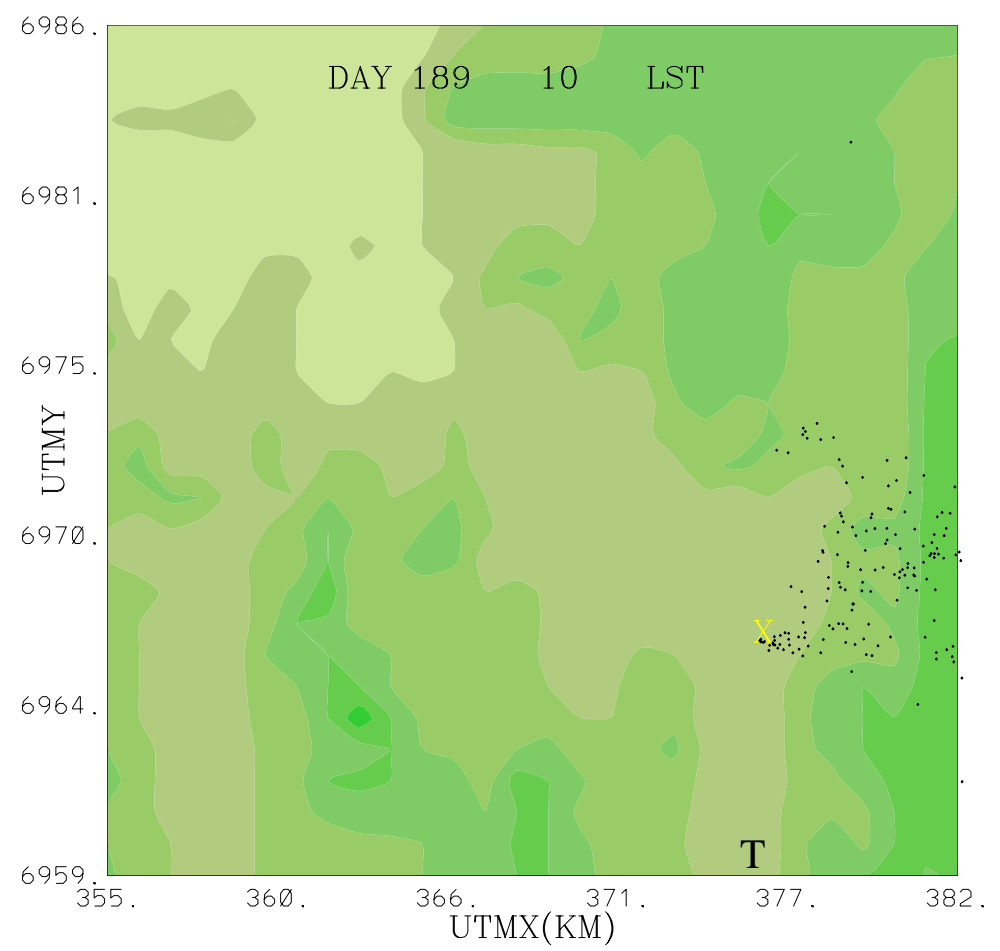

Figure E4. Simulated dispersion for 10 am with the new input and models. 


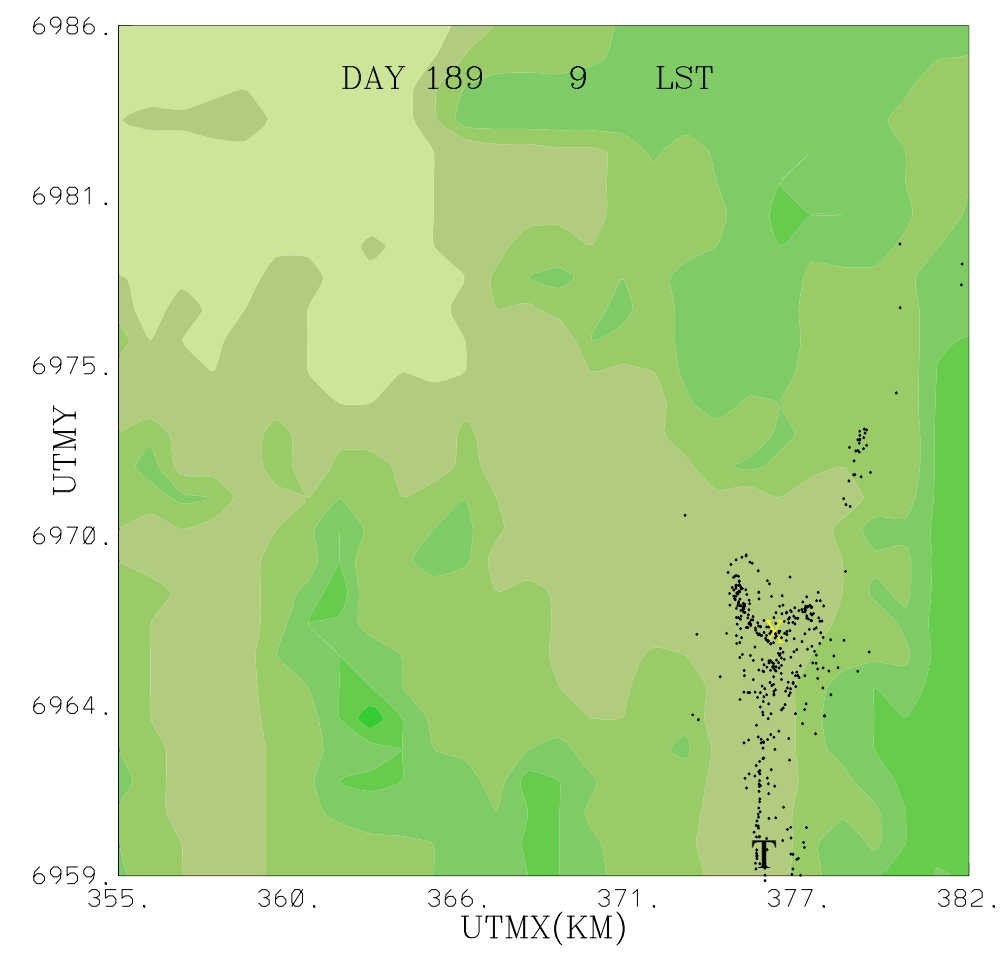

Figure E5. New simulations with tower winds and upper-level winds from the north at 9 am.

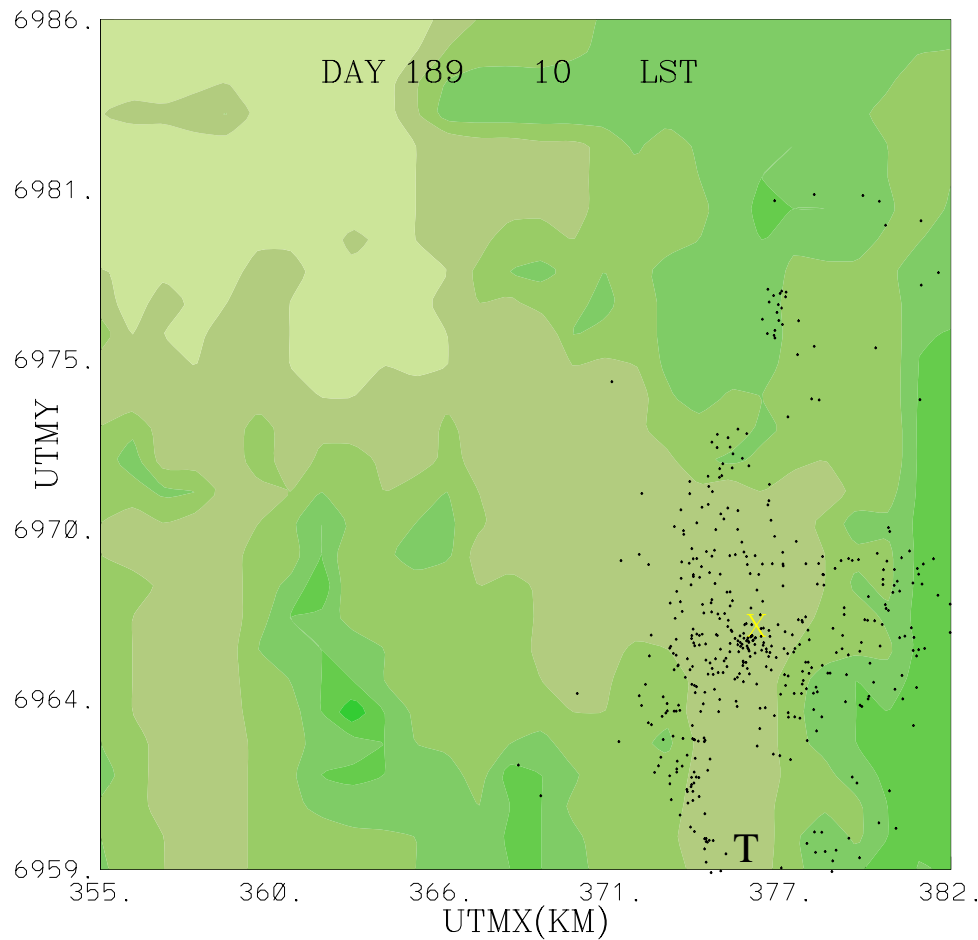

Figure E6. New simulations with upper-level winds from the north at $10 \mathrm{am}$. 


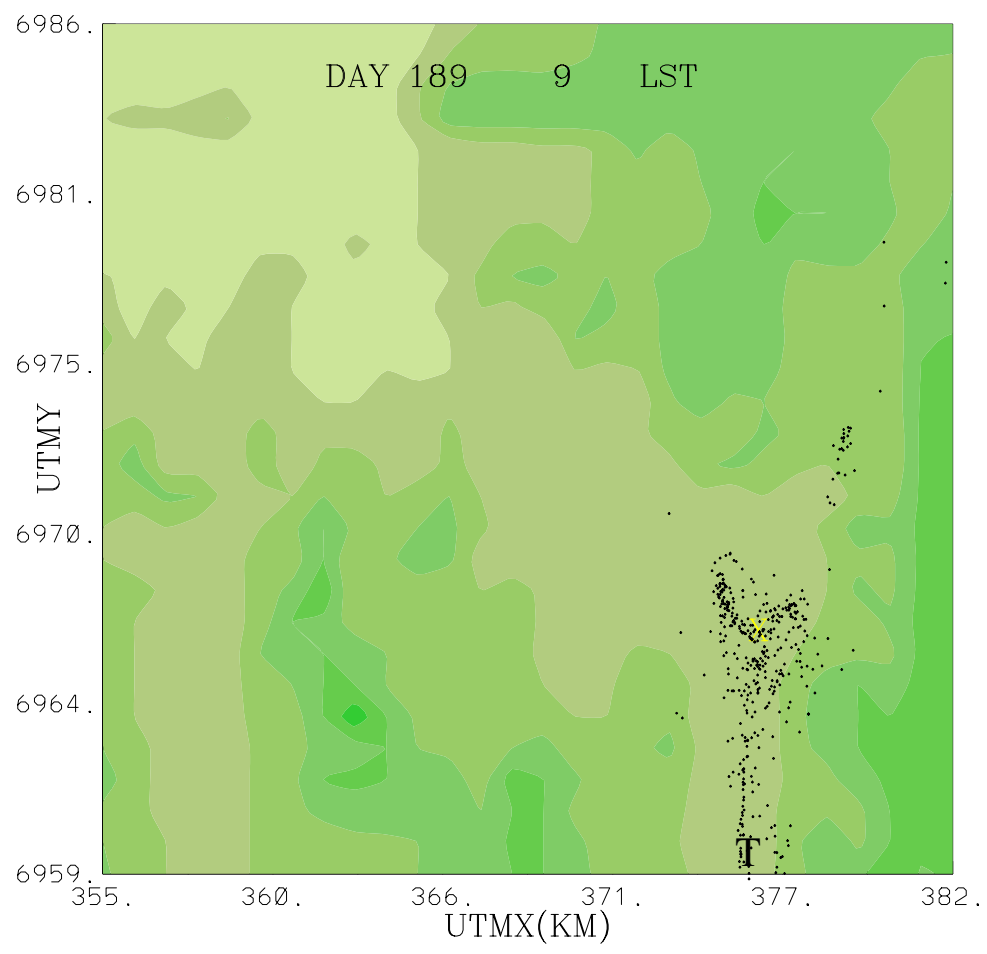

Figure E7. Null-wind, dispersion simulations for 9 am with upper-level winds from the north.

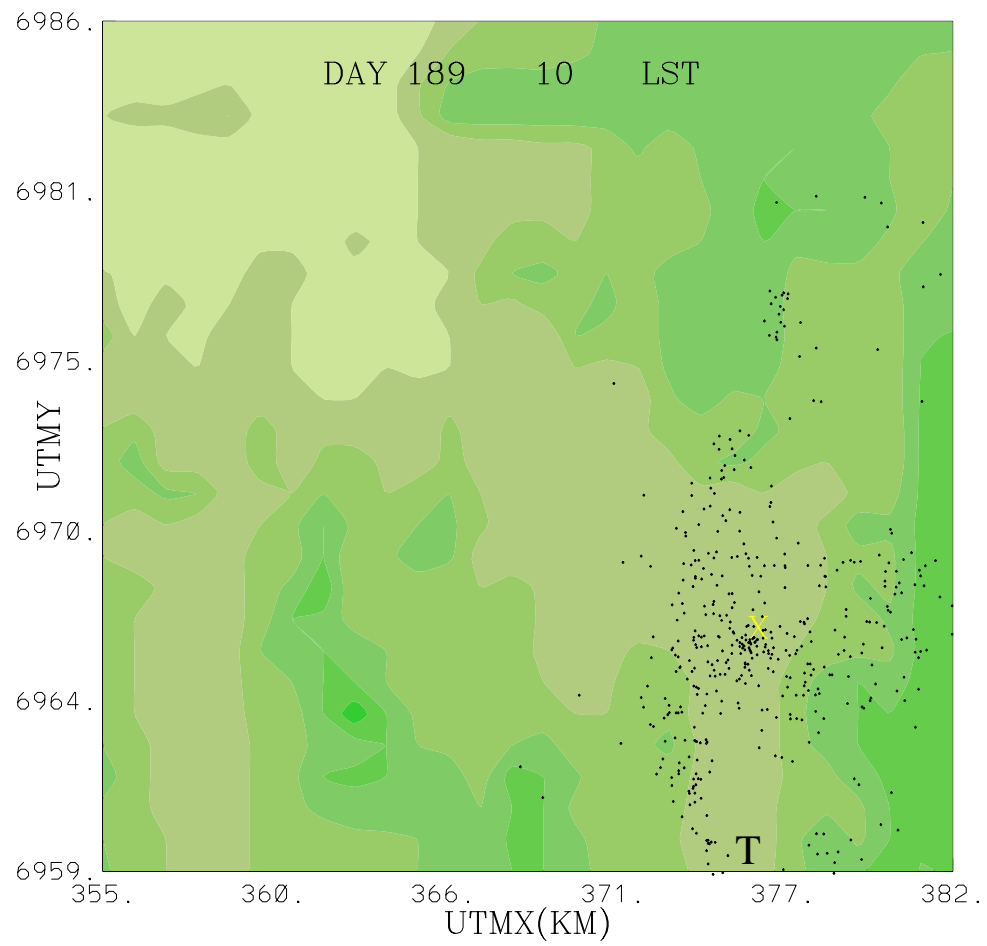

Figure E8. Null-wind, dispersion simulations for $10 \mathrm{am}$. 


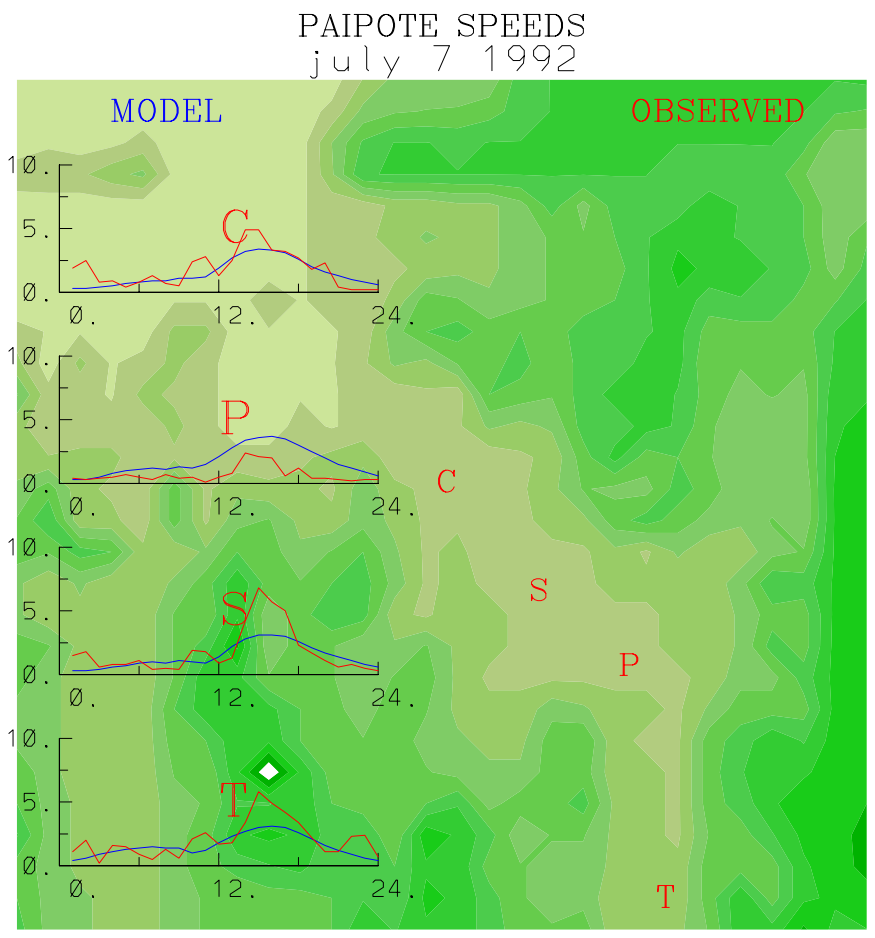

Figure E9. Comparison of observed wind speeds with those modeled with the null-wind case.

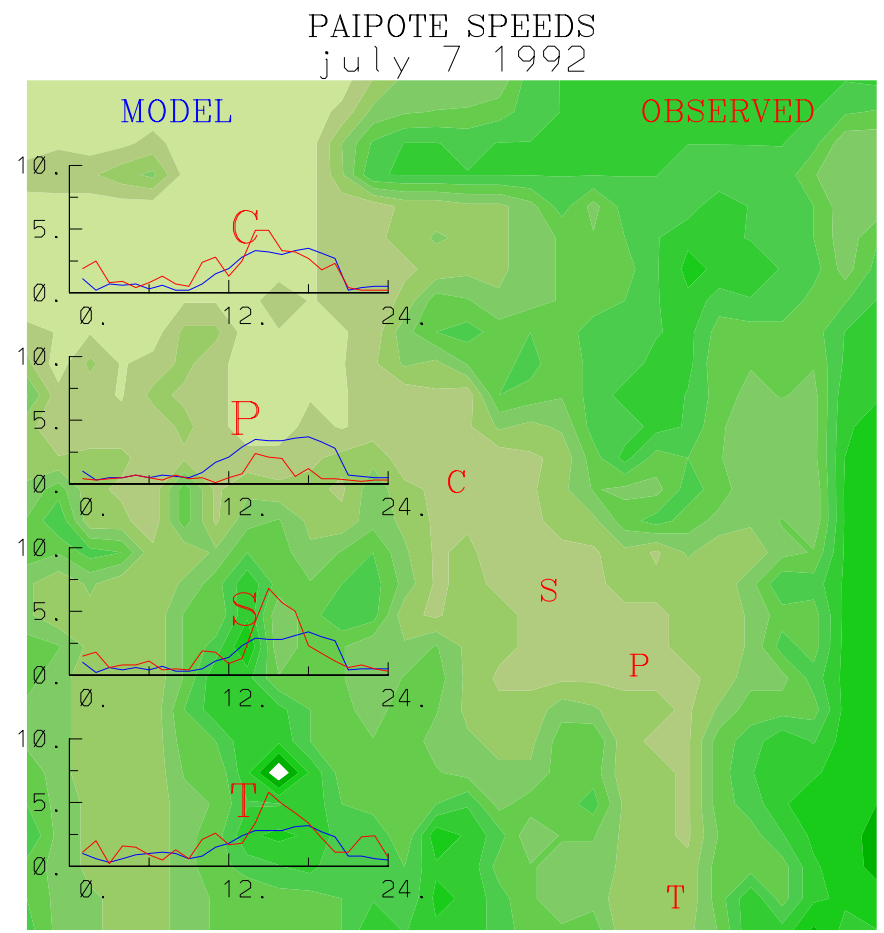

Figure E10. Comparison of observed wind speeds with those modeled with the Tierra Amarilla local winds. 


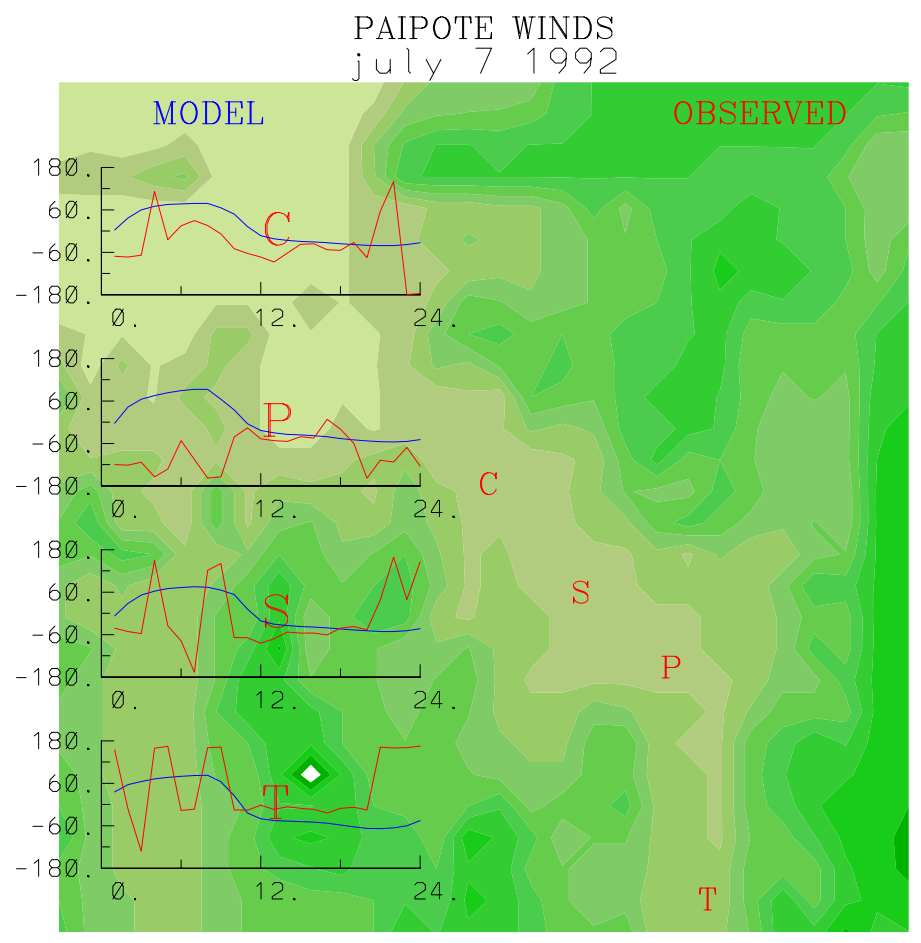

Figure E11. Comparison of observed wind directions with those of the null case.

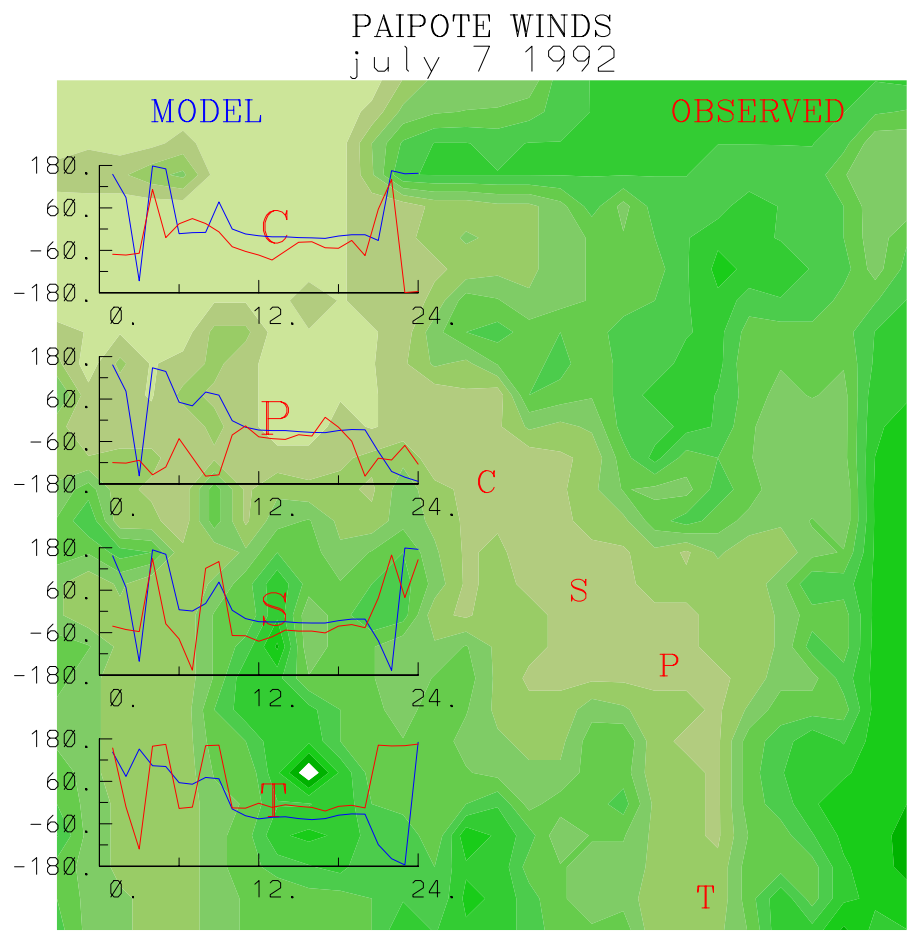

Figure E12. Comparison of observed wind directions with those of the Tierra Amarilla local wind case. 


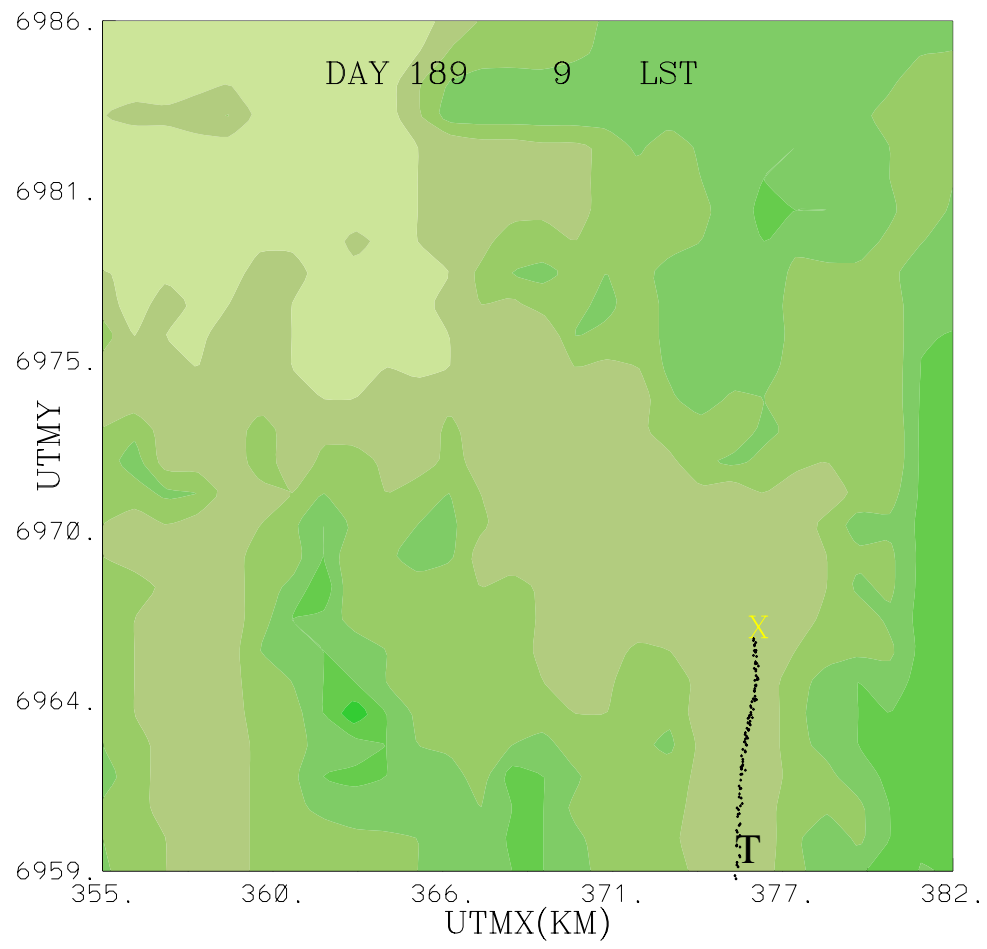

Figure E13. Simulated dispersion with Tierra Amarilla local winds for 9 am.

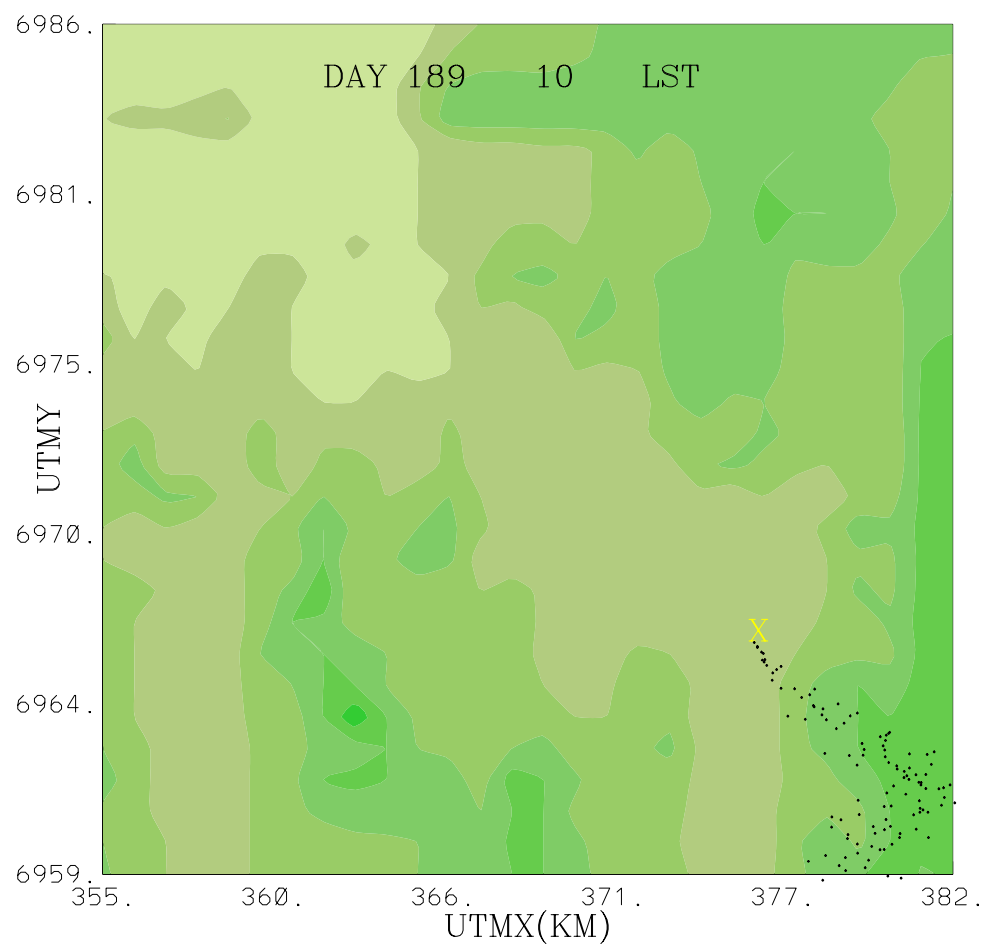

Figure E14. Simulated dispersion with Tierra Amarilla local winds for $10 \mathrm{am}$. 


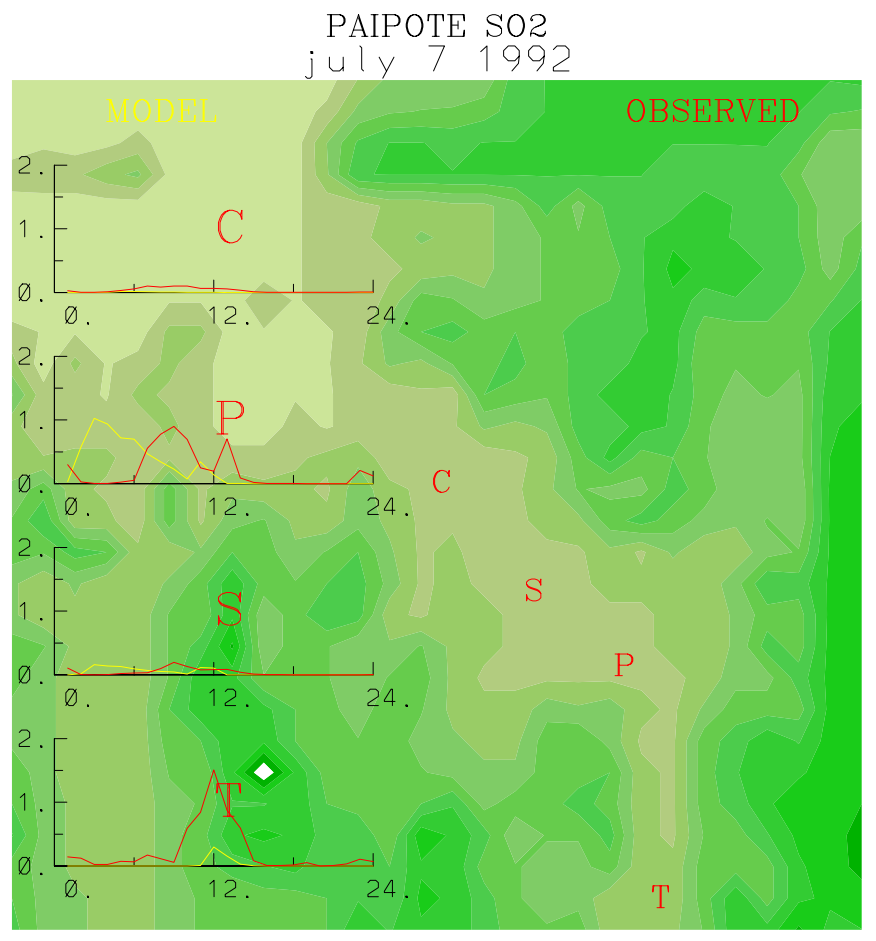

Figure E15. Comparison between observed SO2 measurements and those modeled with the old codes and assumptions.

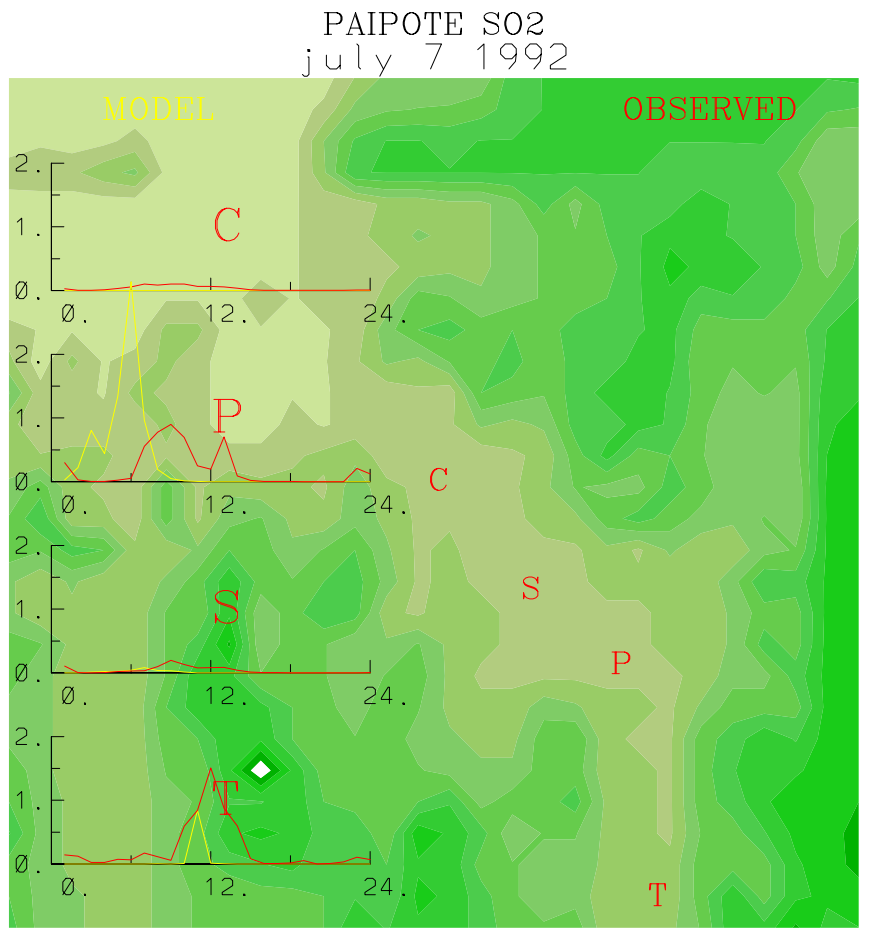

Figure E16. Comparison between observed SO2 measurements and those modeled with local winds from Tierra Amarilla and upper-level winds from the north. 


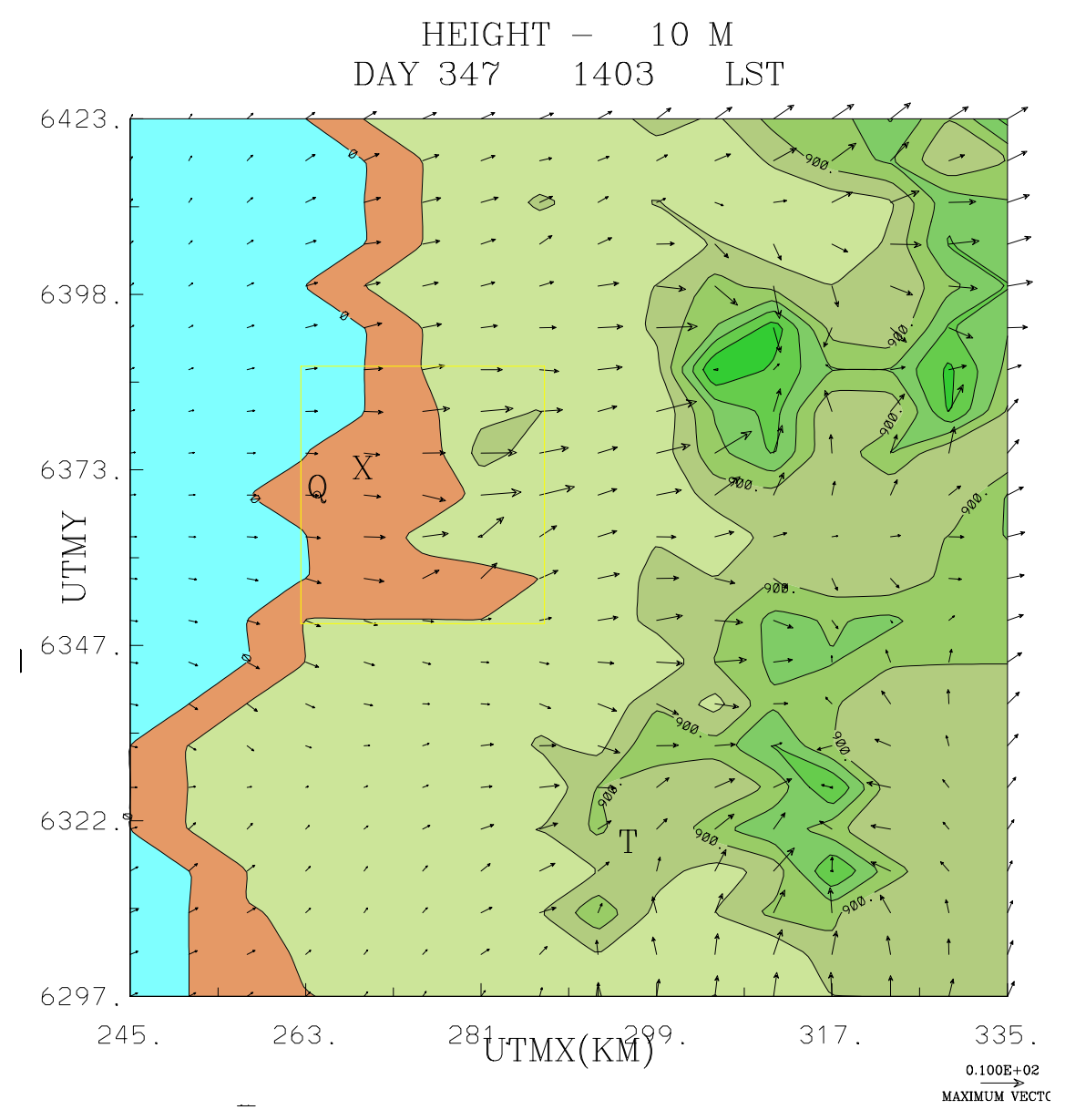

b)

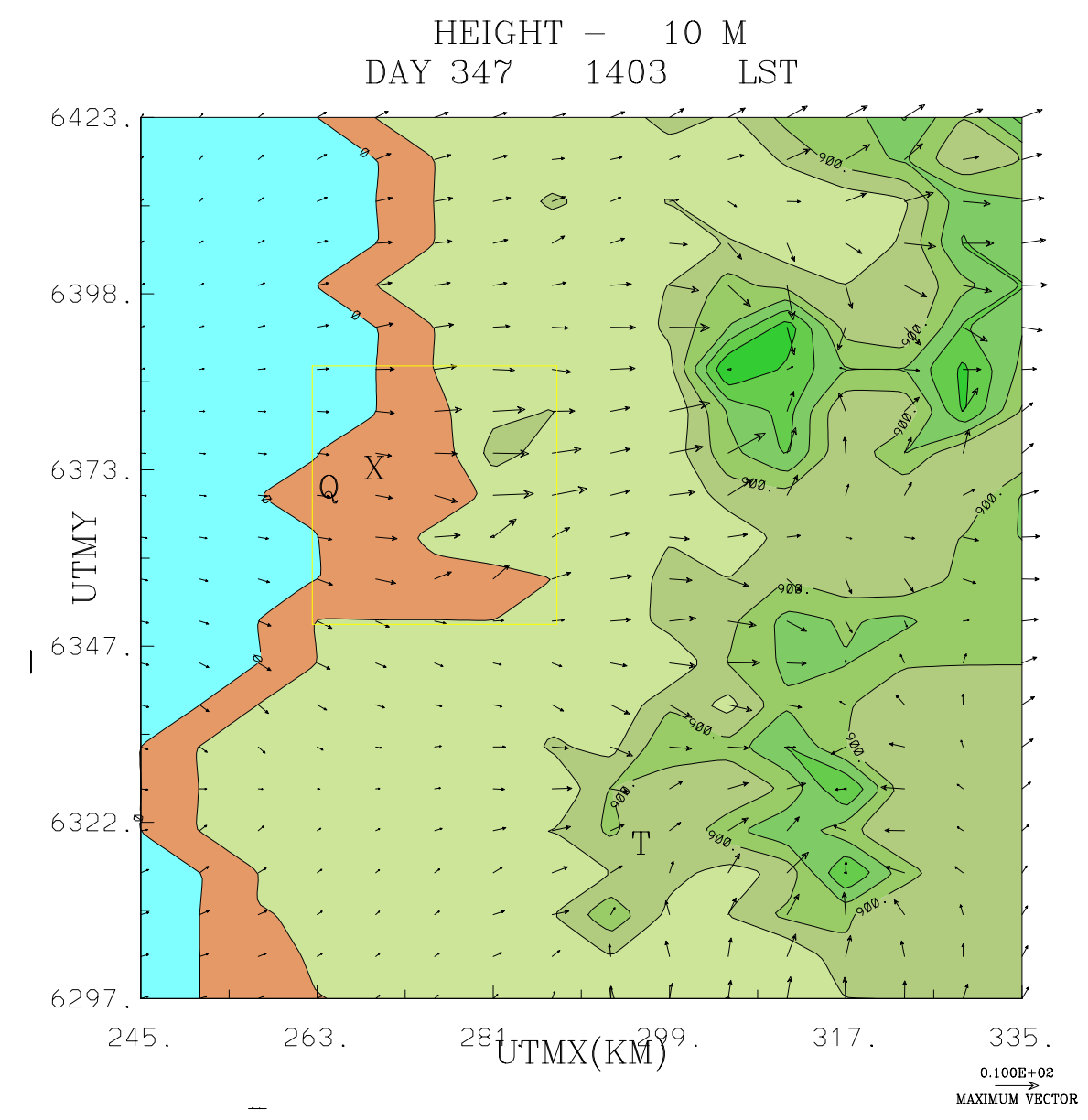

Figure F1. Typical daytime horizontal winds computed by the HOTMAC model for prevailing wind direction equal to a) 180 and b) 360 degrees. Computed on the intermediate grid at a $10 \mathrm{~m}$ height. 


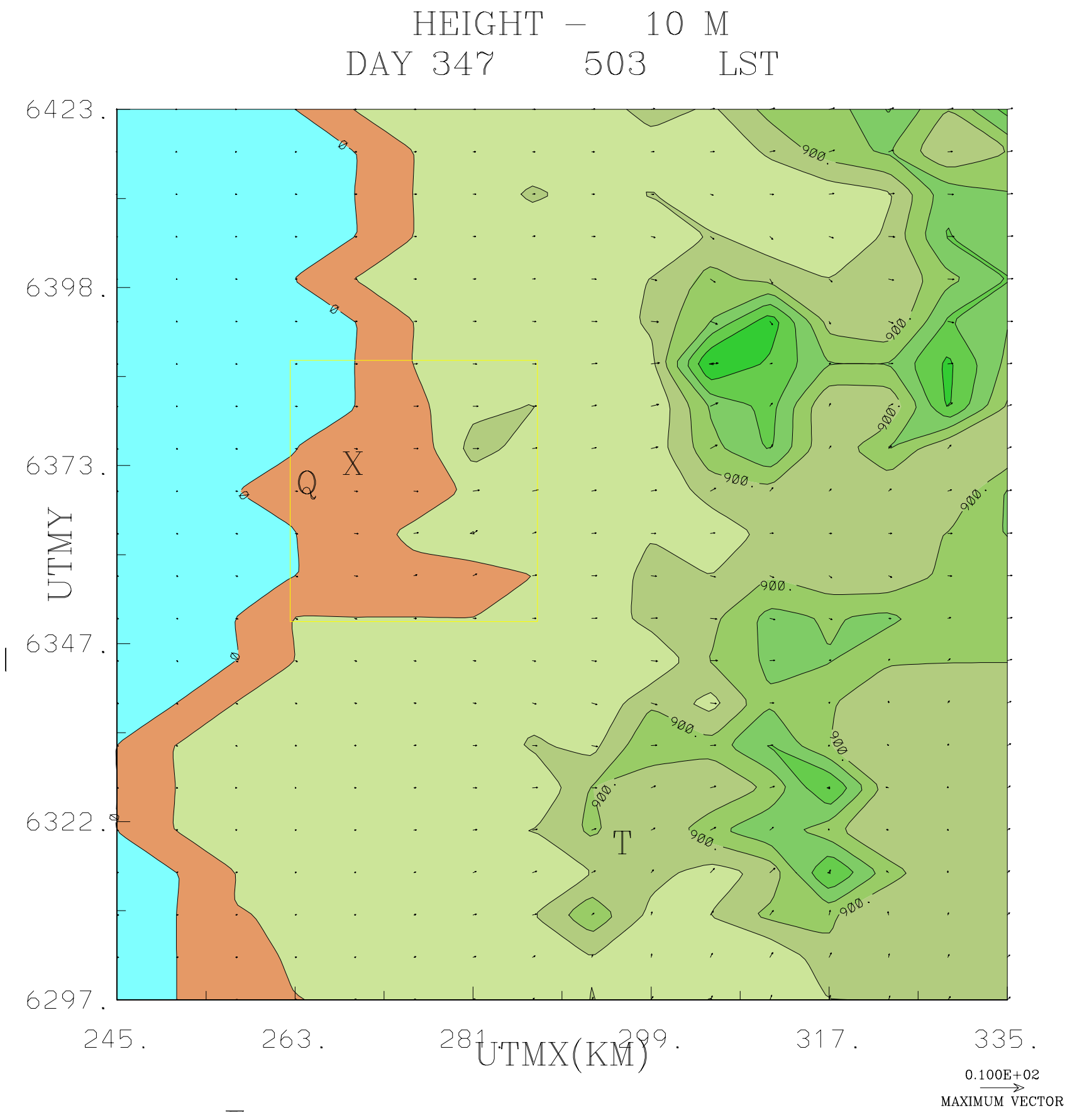

Figure F2. Typical night time horizontal winds computed by the HOTMAC model for prevailing wind direction equal to 270 degrees. Computed on the intermediate grid at a $10 \mathrm{~m}$ height. 

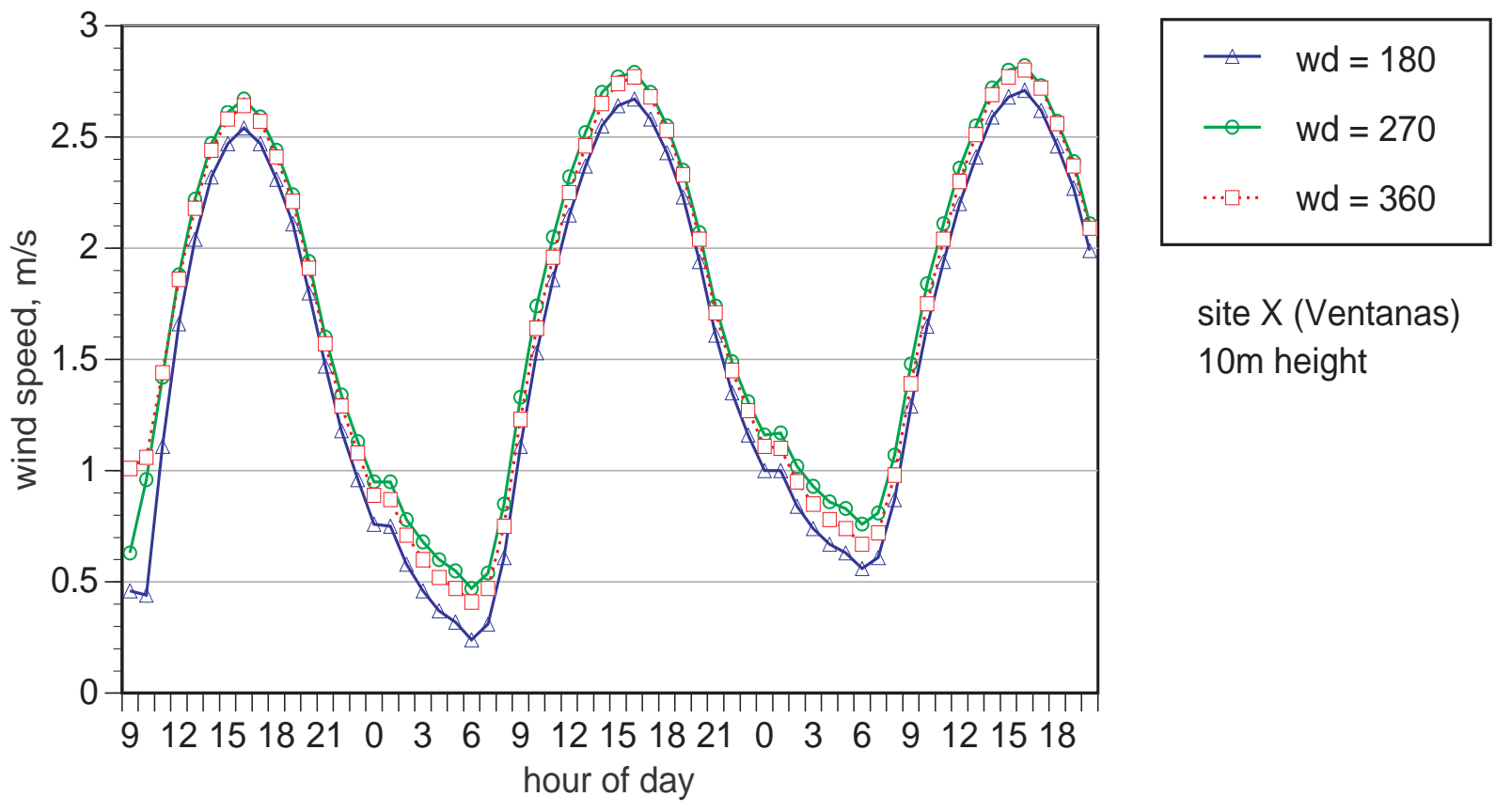

site $X$ (Ventanas)

$10 \mathrm{~m}$ height
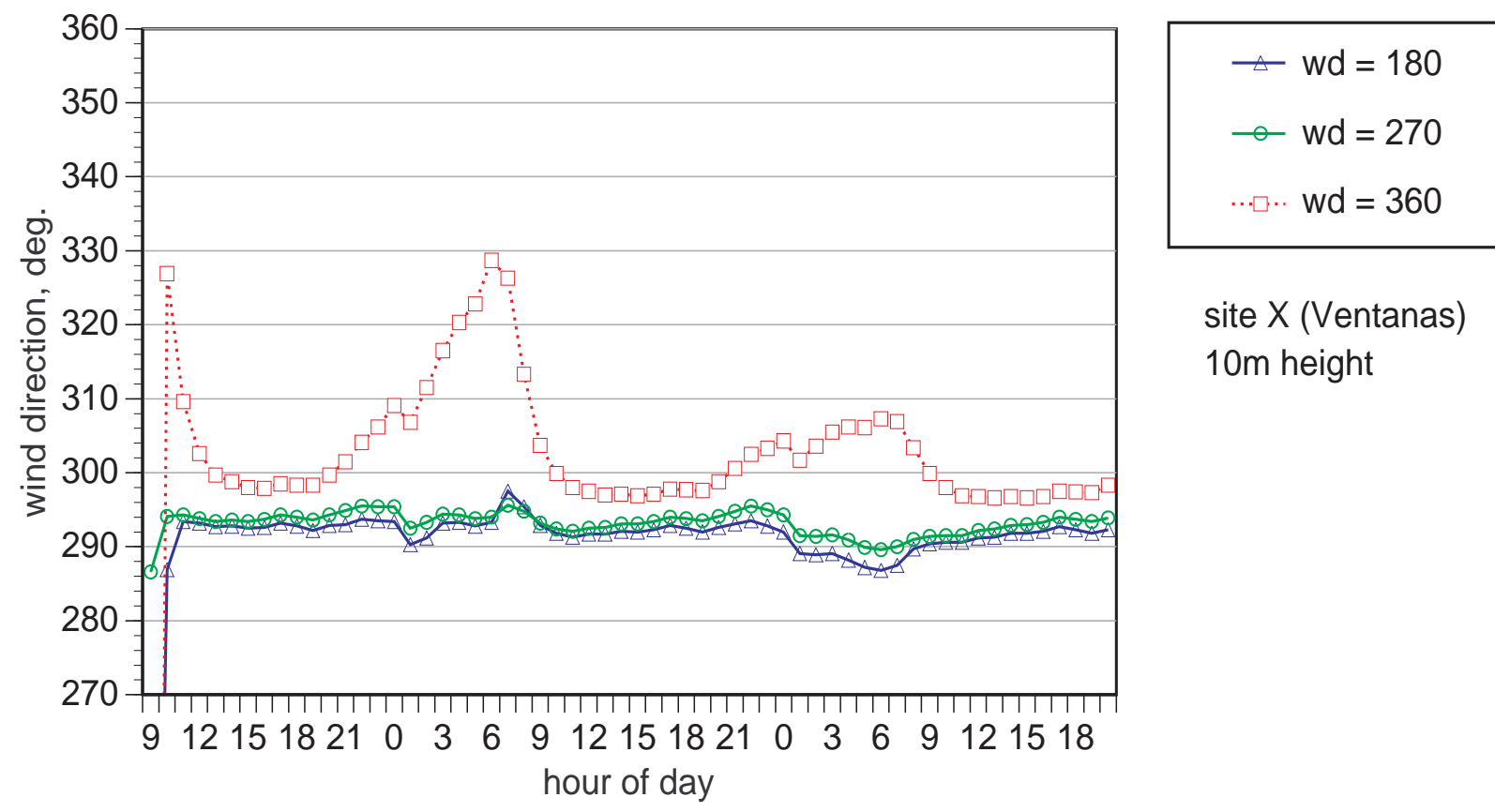

site $\mathrm{X}$ (Ventanas)

$10 \mathrm{~m}$ height

Figure F3. Model-computed wind speed and wind direction versus time for three different prevailing wind directions. Computations made at the Ventanas site at a height of $10 \mathrm{~m}$. Simulation started 8:00 am on Dec. 11. 

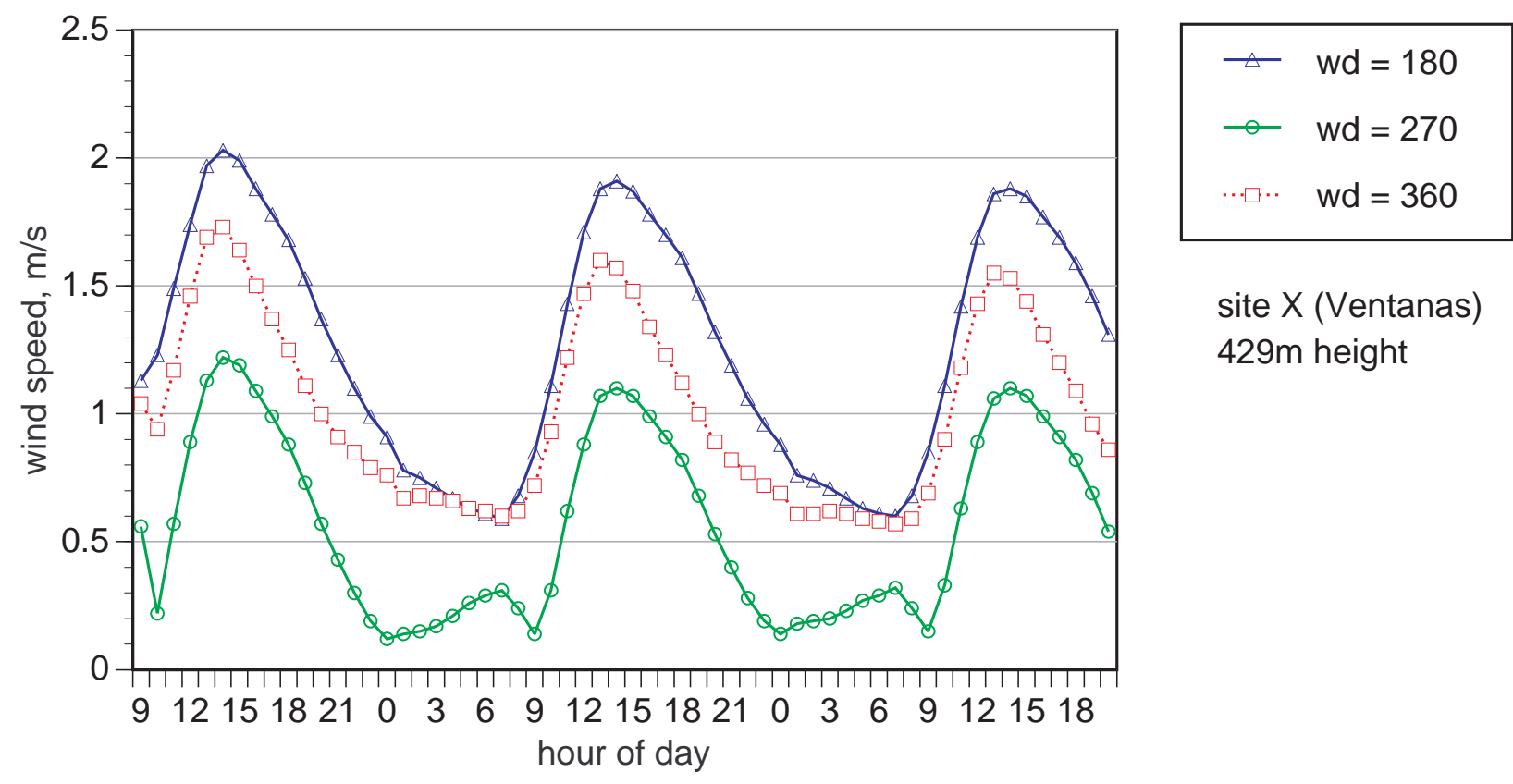

site $\mathrm{X}$ (Ventanas)

$429 m$ height
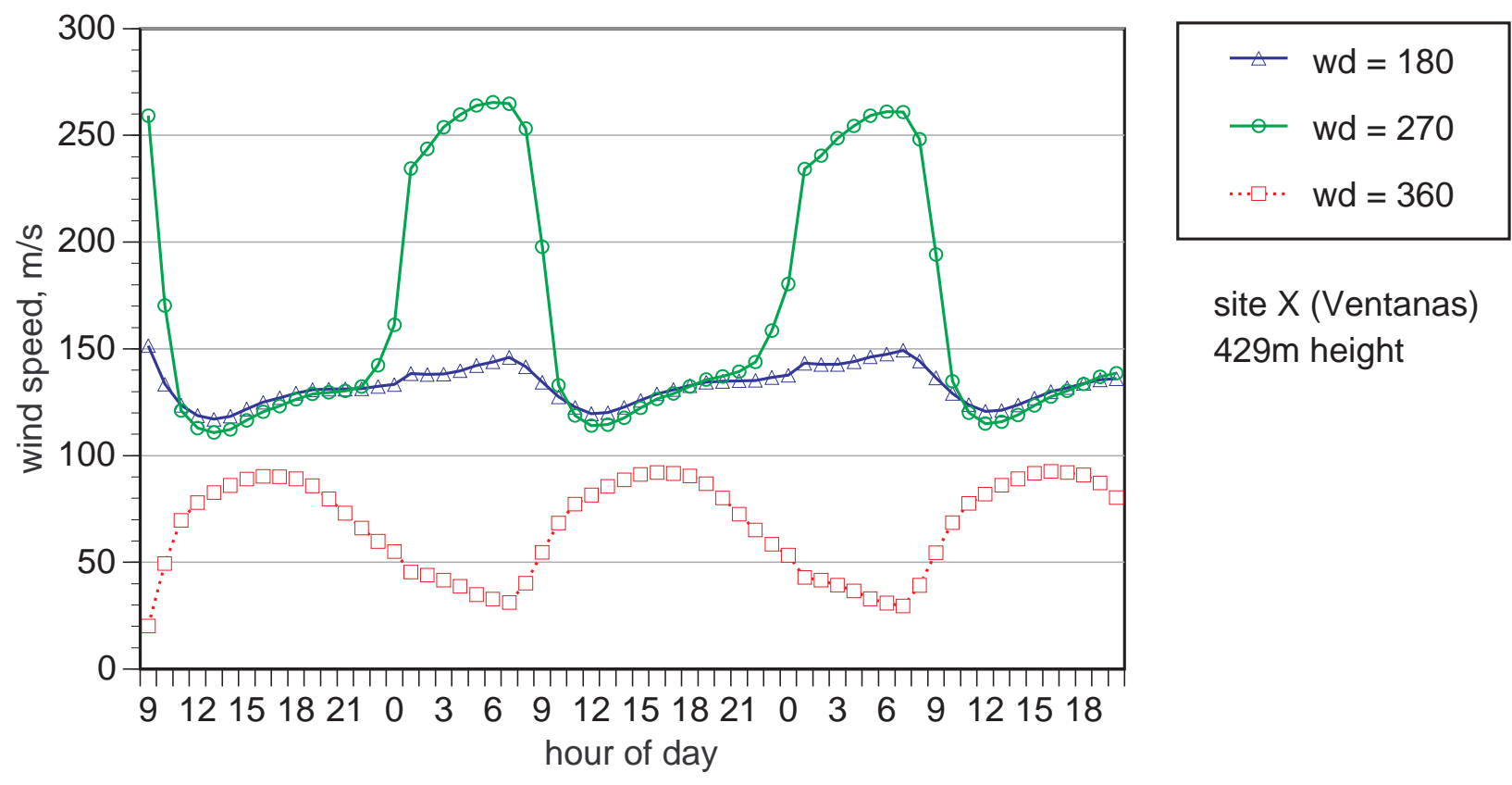

site $\mathrm{X}$ (Ventanas)

$429 \mathrm{~m}$ height

Figure F4. Model-computed wind speed and wind direction versus time for three different prevailing wind directions. Computations made at the Ventanas site at a height of $429 \mathrm{~m}$. Simulation started 8:00 am on Dec. 11. 


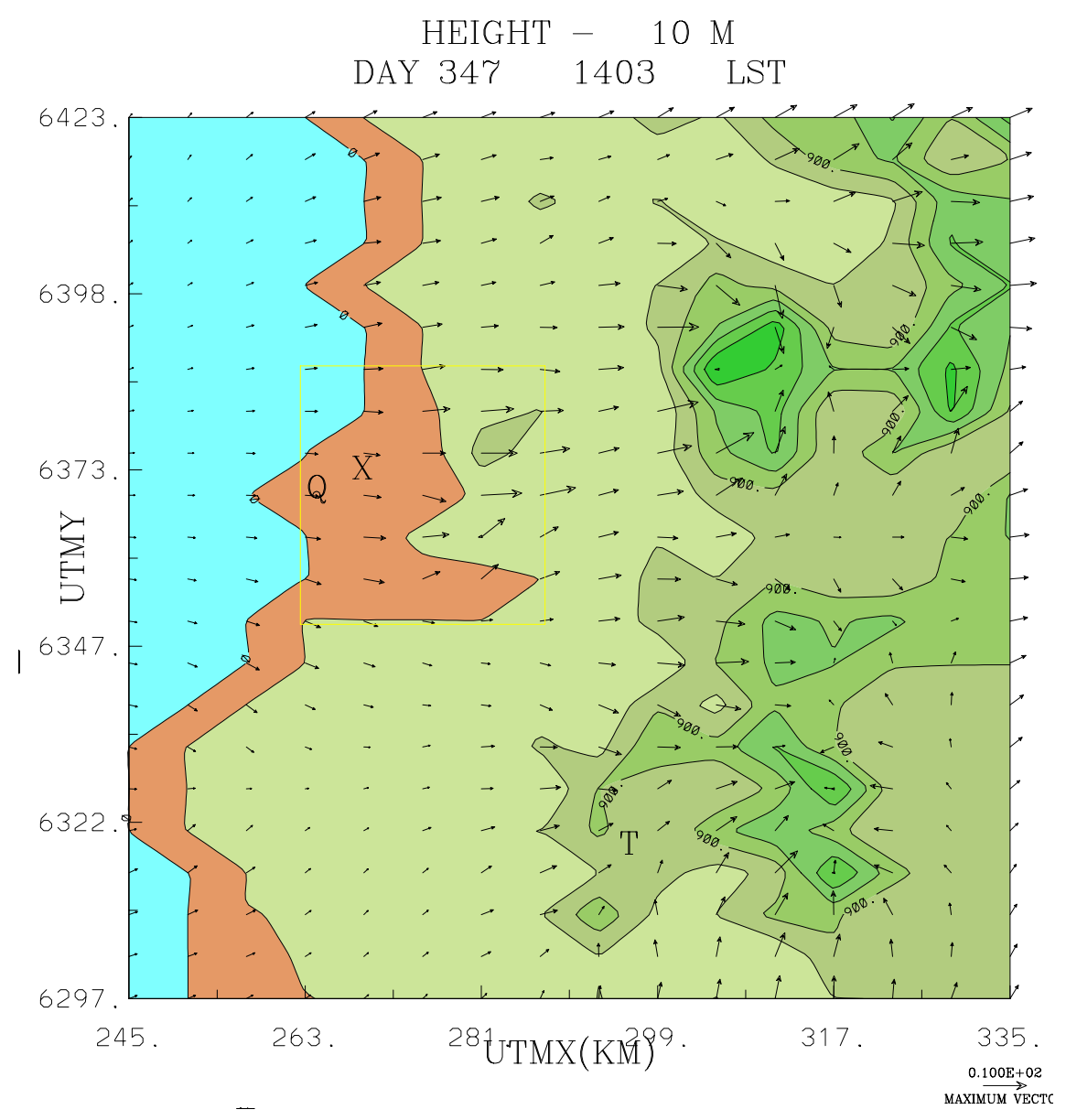

b)

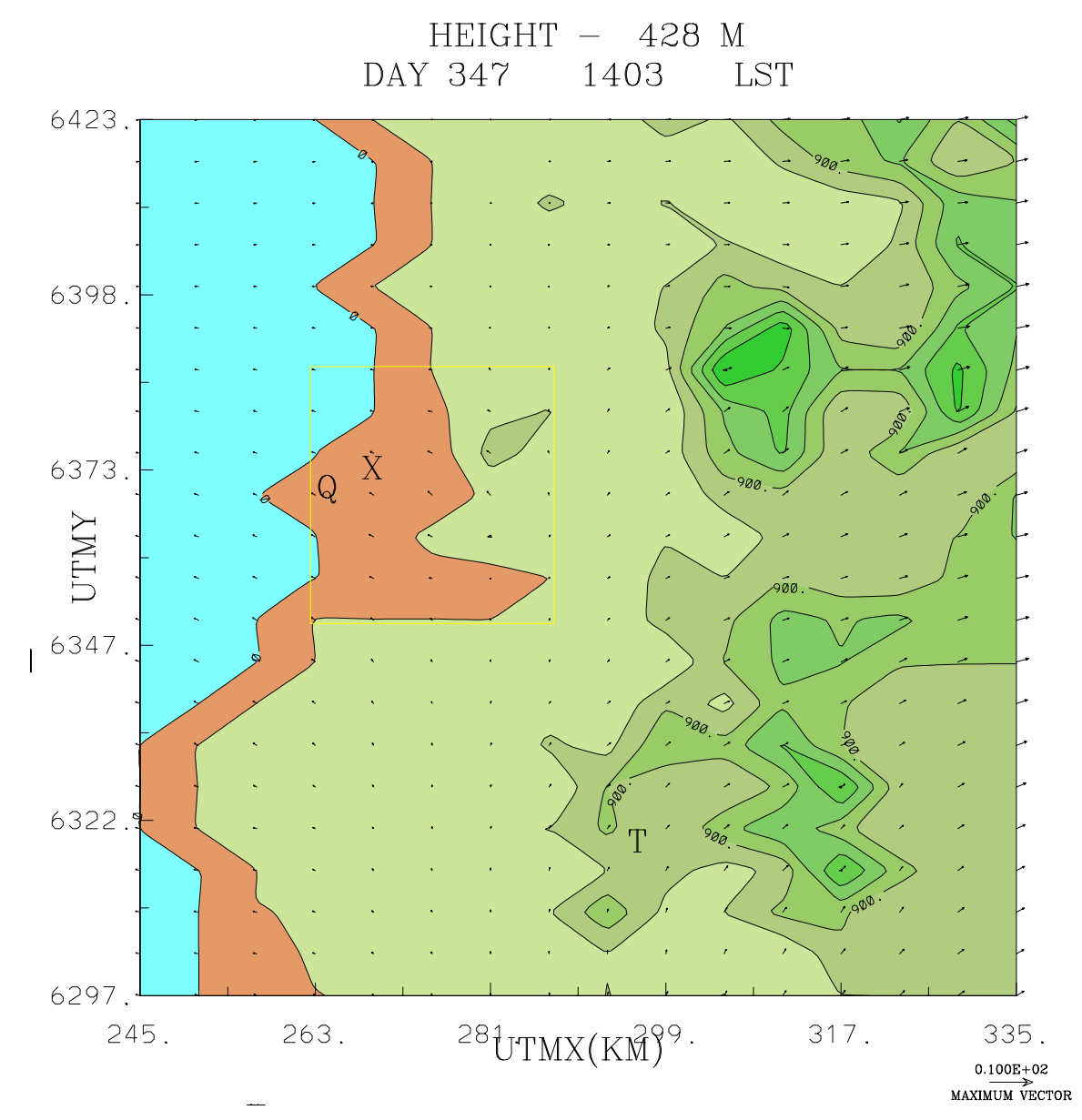

Figure F5. Typical afternoon horizontal winds computed by the HOTMAC model at a height of a) 10 and b) 428 meters. Computed on the intermediate grid with a prevailing wind direction of 270 degrees. Notice the sea-breeze circulation.. 
a)

PLUME SIMULATION

DAY 3475 LST

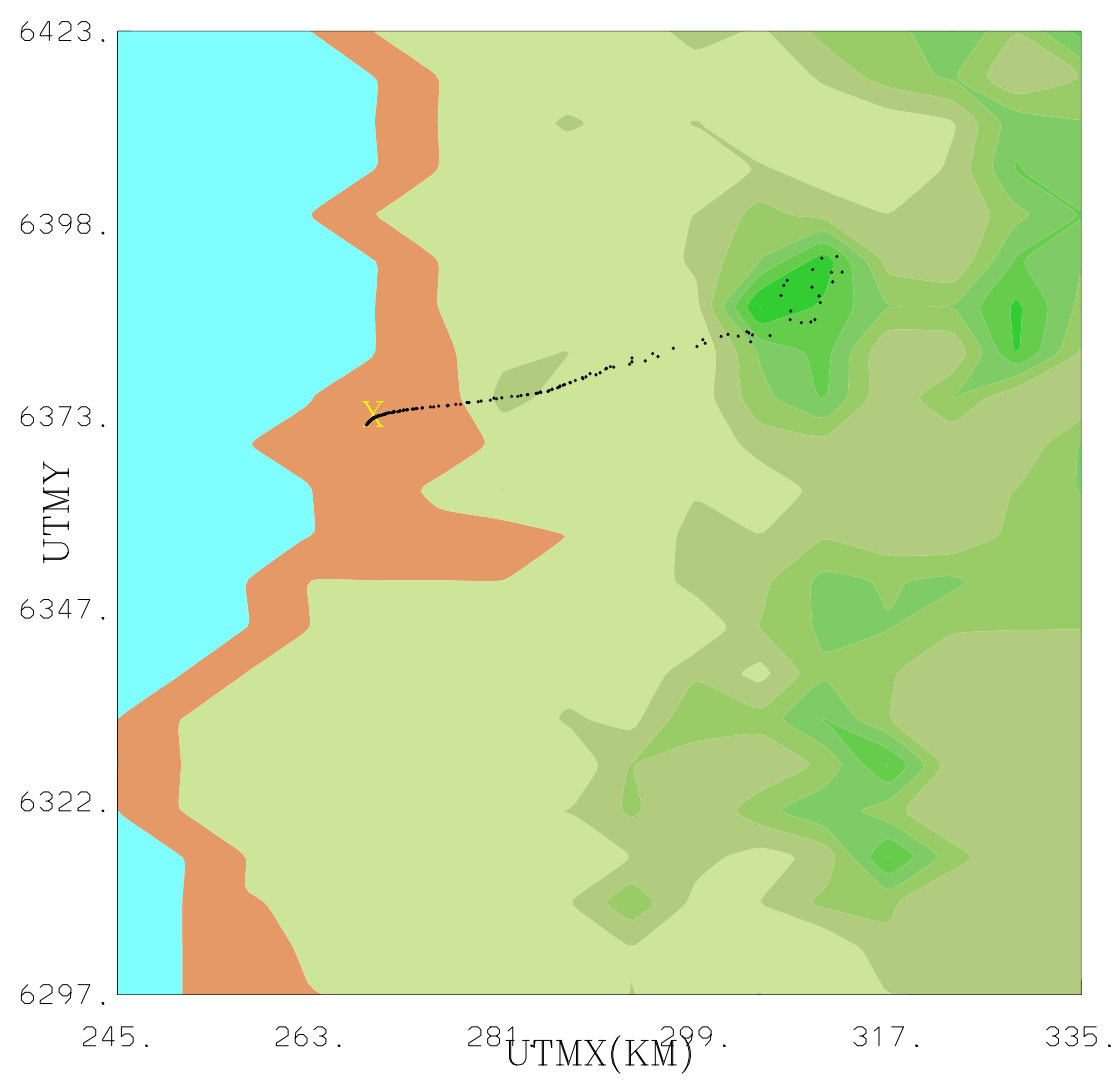

b)

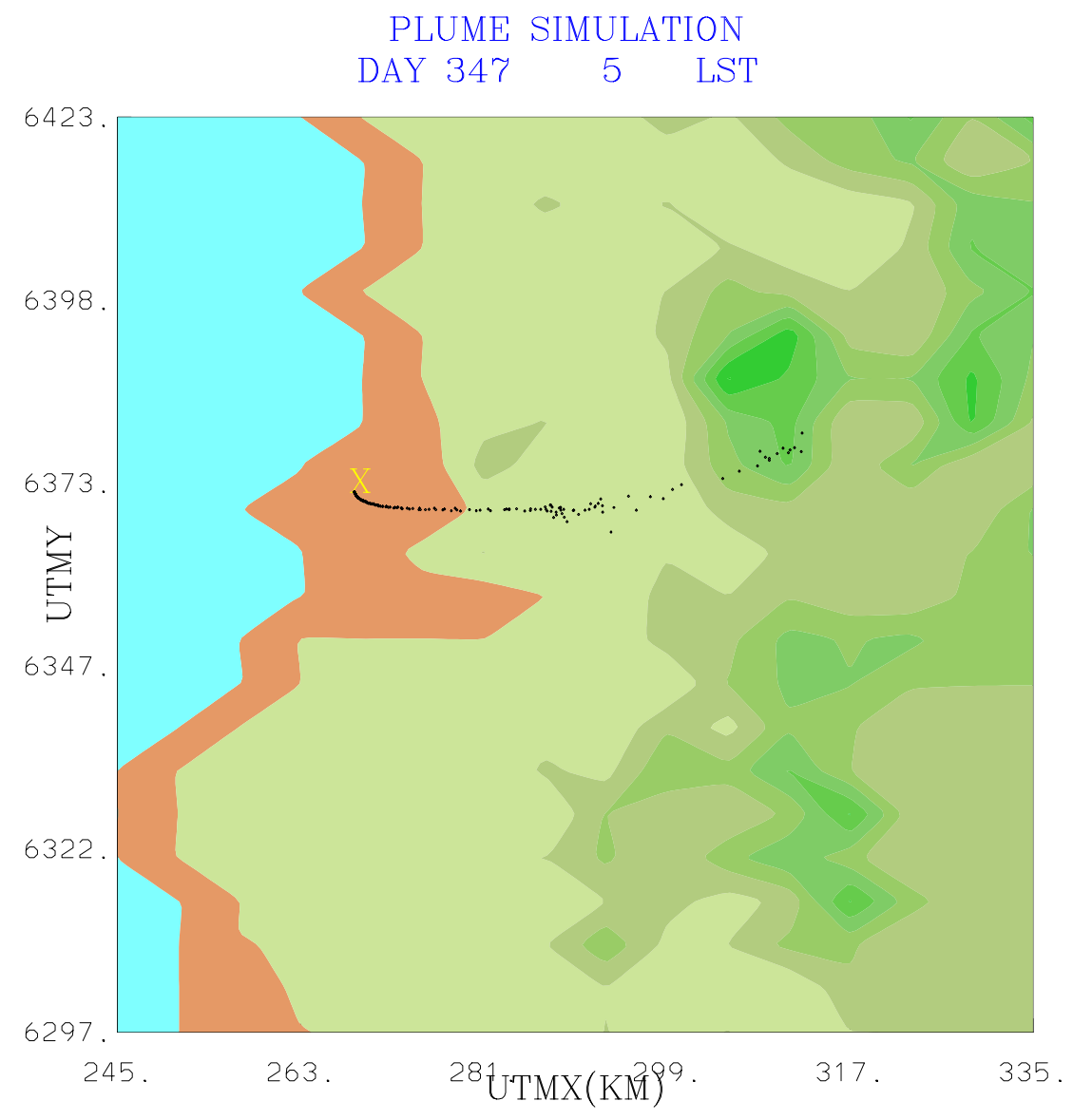

Figure F6. Ventanas plume simulated by the RAPTAD model for prevailing wind direction equal to a) 180 and b) 360 degrees. Current time: 5 am, Dec. 12. Plume release began at 9 pm, Dec. 11. 
a)

PLUME SIMULATION

DAY $347 \quad 11$ LST

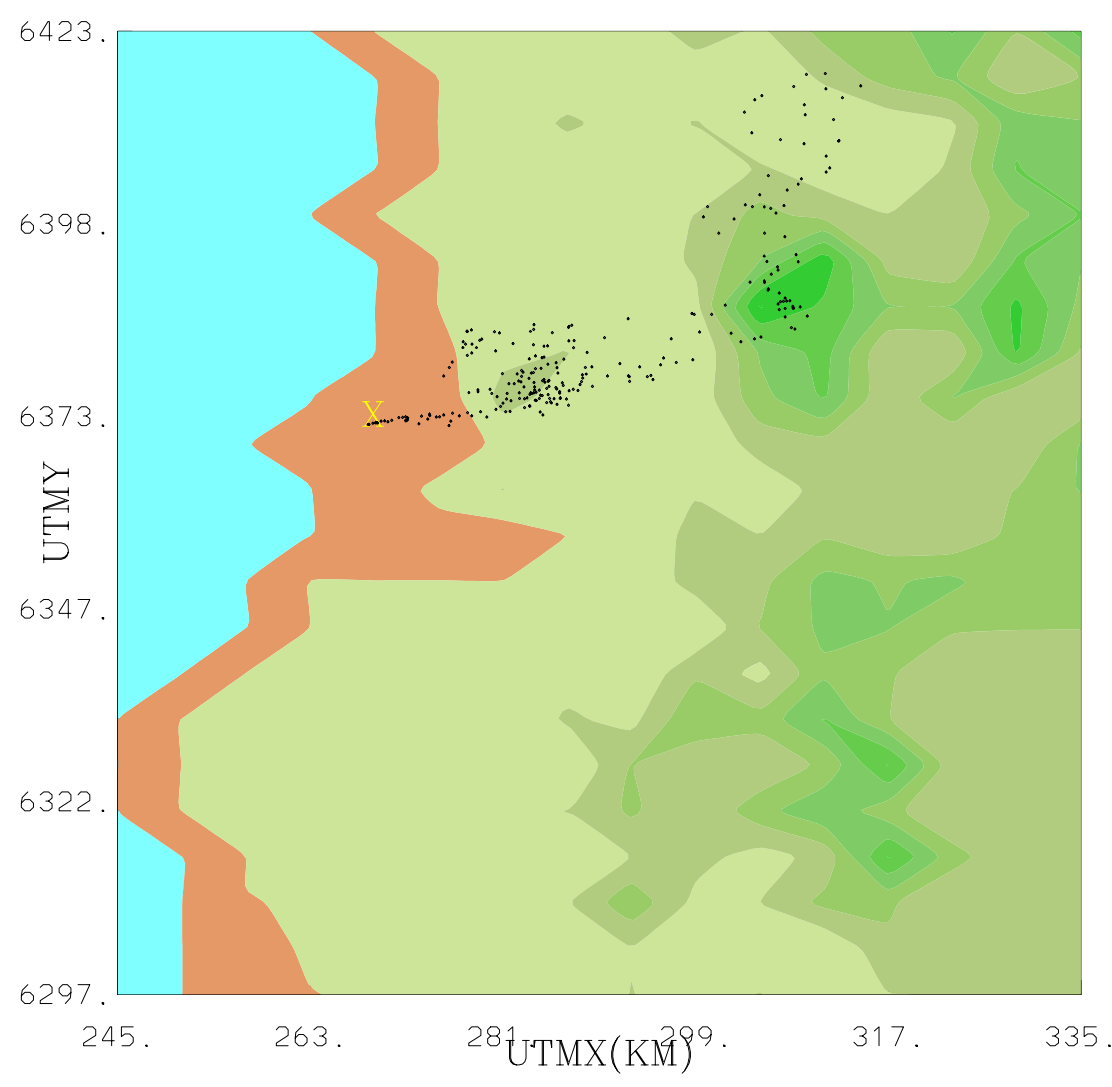

b)

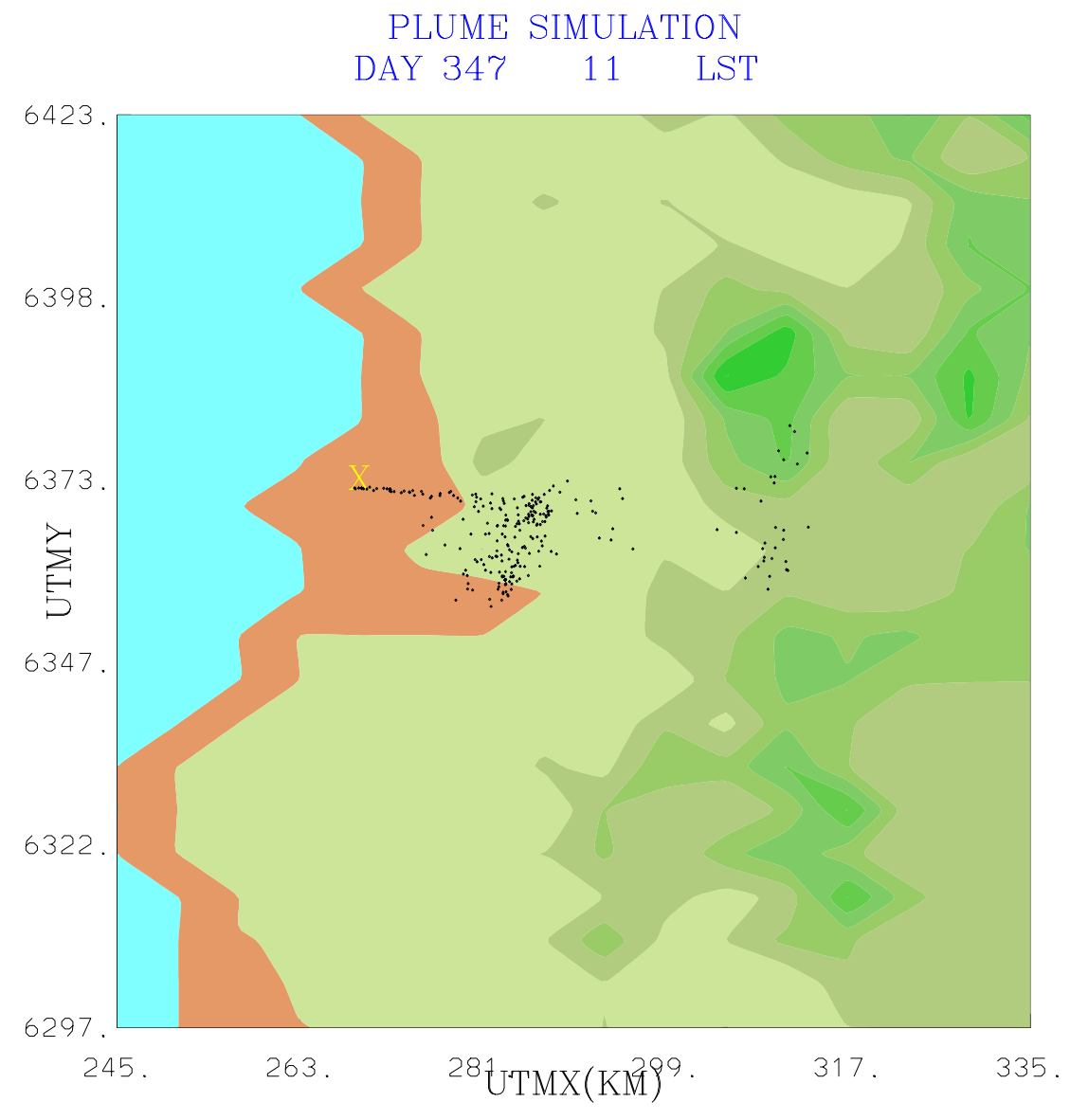

Figure F7. Ventanas plume simulated by the RAPTAD model for prevailing wind direction equal to a) 180 and b) 360 degrees. Current time: 11 am, Dec. 12. Plume release began at 9 pm, Dec. 11. 
a)

PLUME SIMULATION

DAY $347 \quad 14$ LST

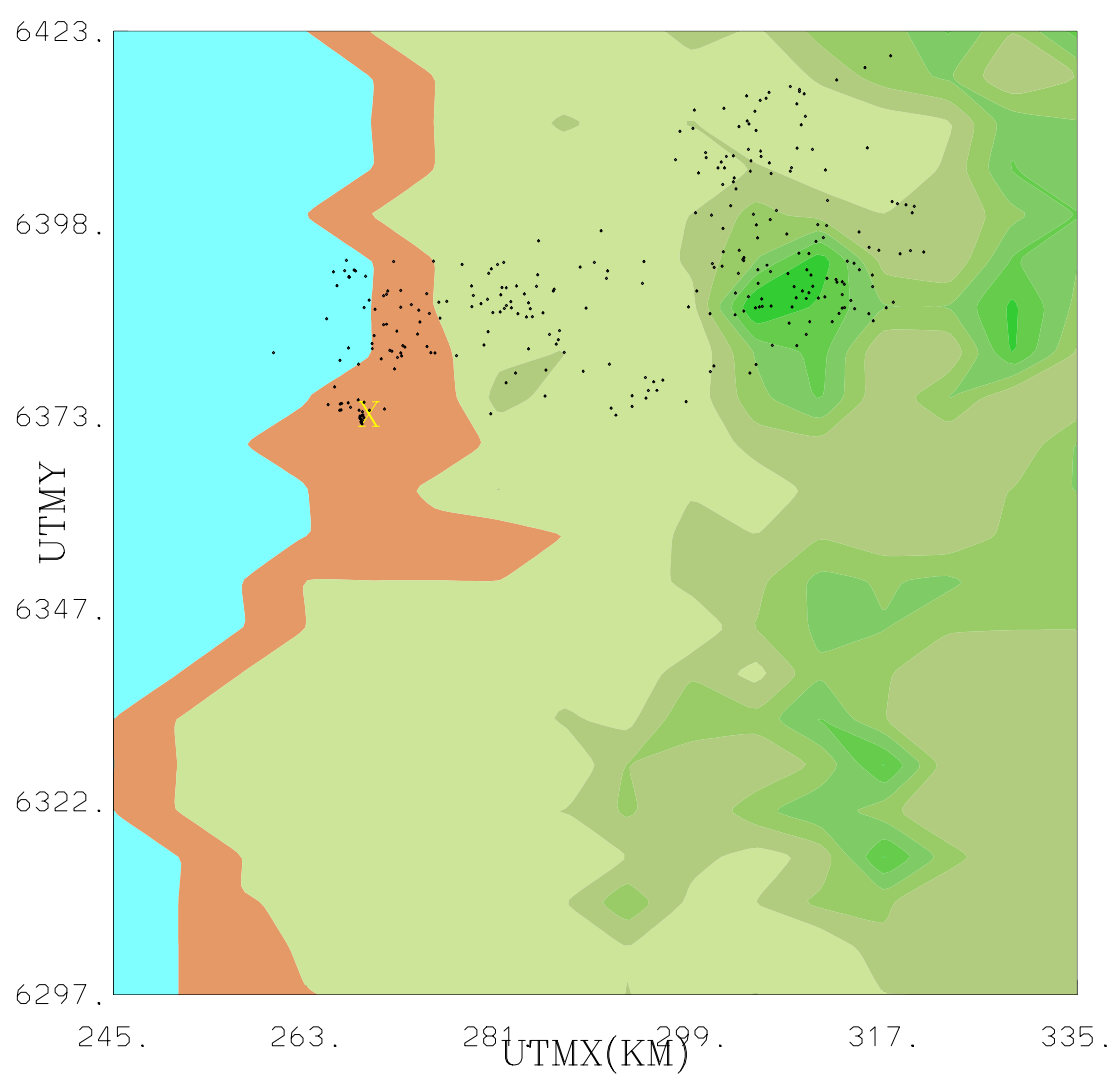

b)

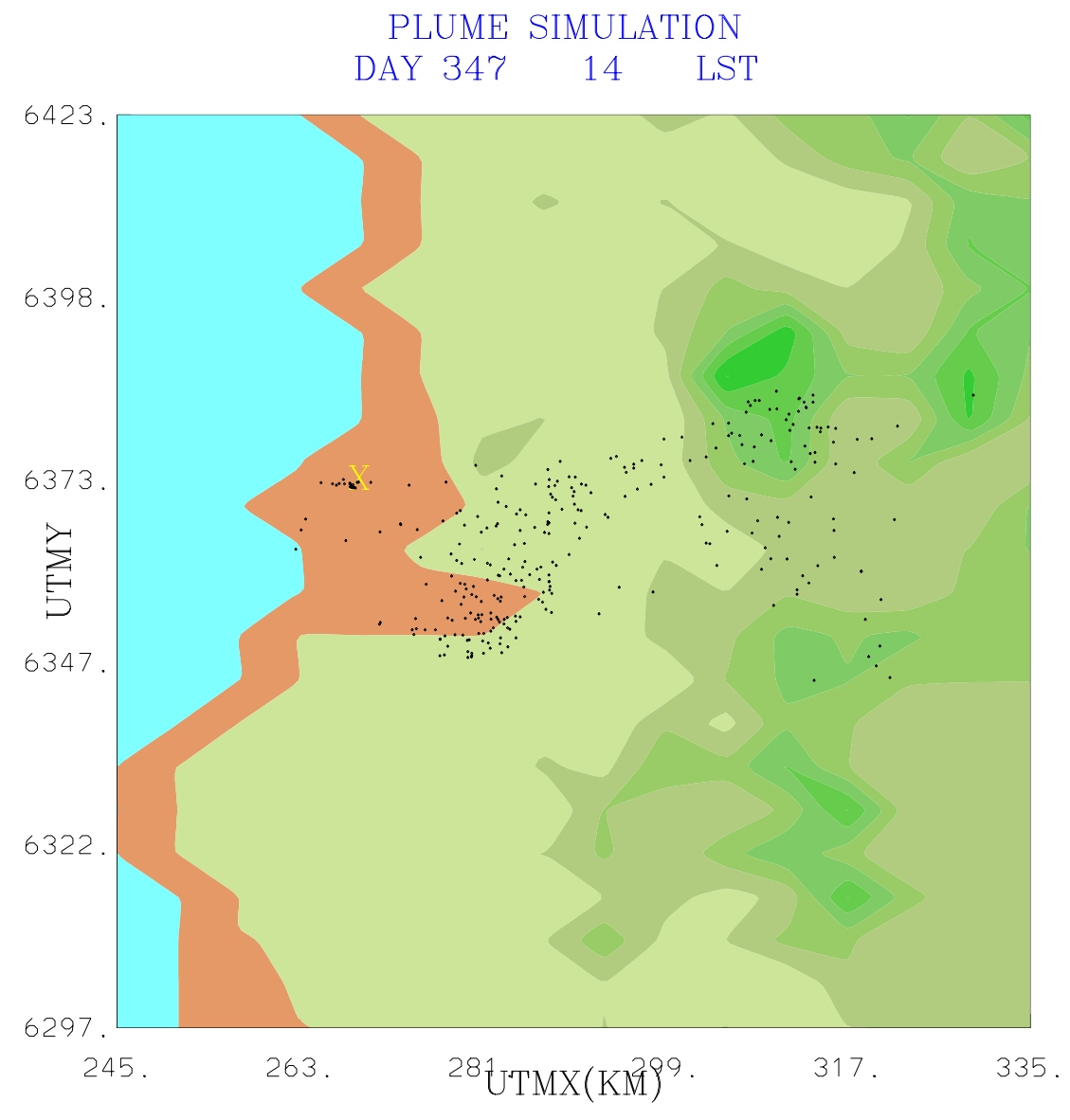

Figure F8. Ventanas plume simulated by the RAPTAD model for prevailing wind direction equal to a) 180 and b) 360 degrees. Current time: 2 pm, Dec. 12. Plume release began at 9 pm, Dec. 11. 


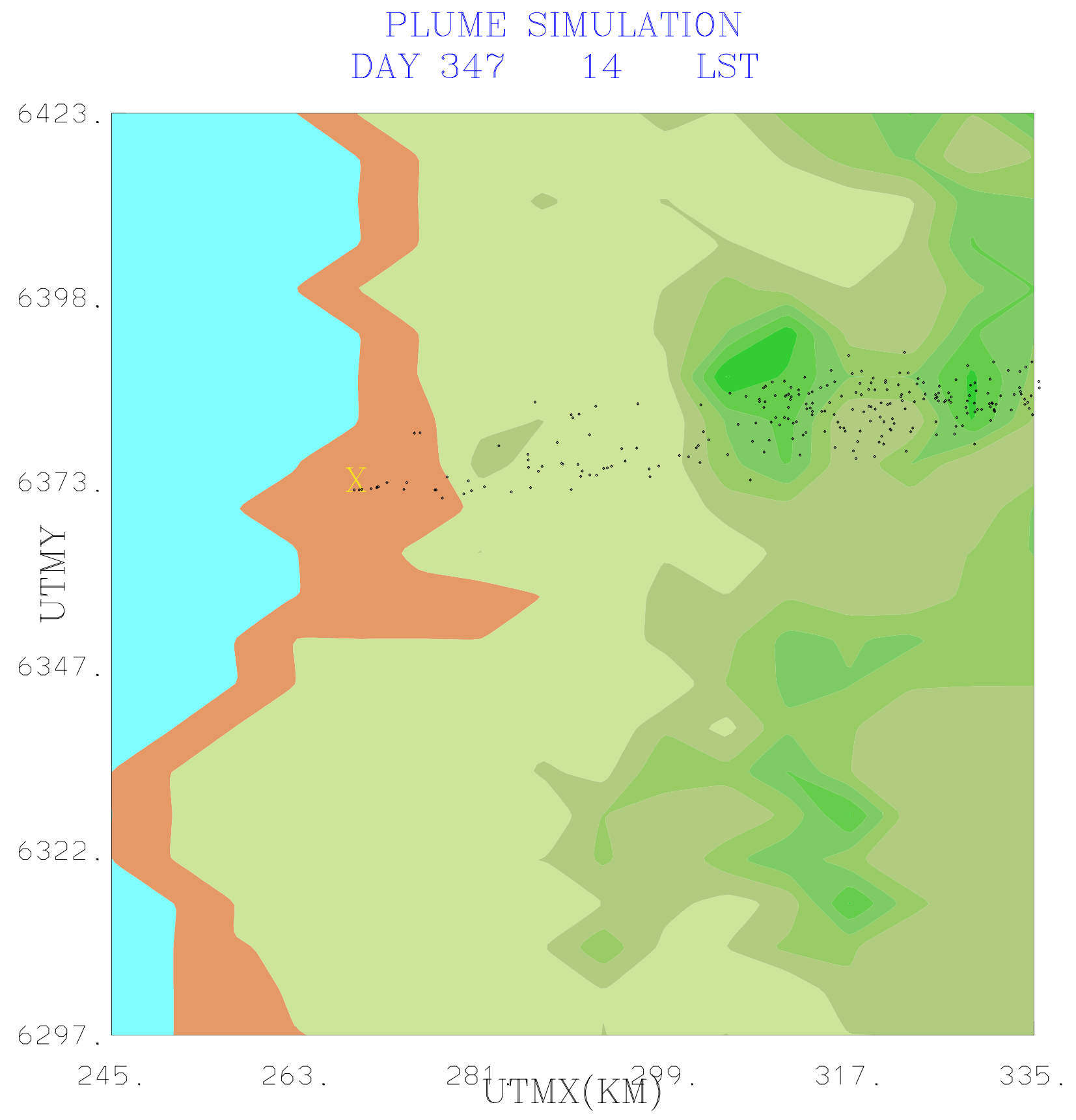

Figure F9. Ventanas plume simulated by the RAPTAD model for prevailing wind direction equal to 270 degrees. Current time: 2 pm, Dec. 12.. Plume release began at 9 pm on Dec. 11. 
a)

PLUME SIMULATION

DAY $347 \quad 18 \quad$ LST

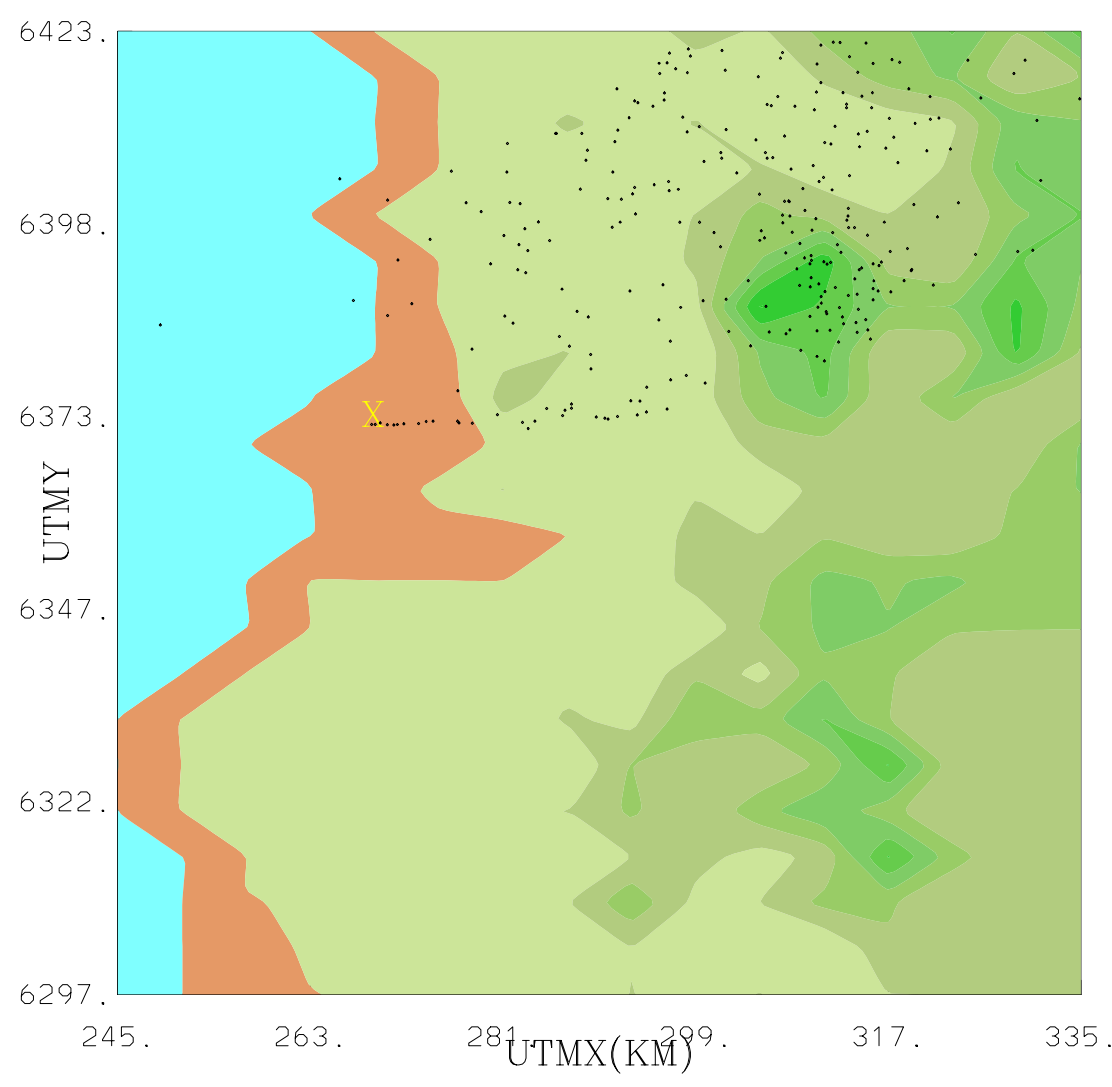

b)

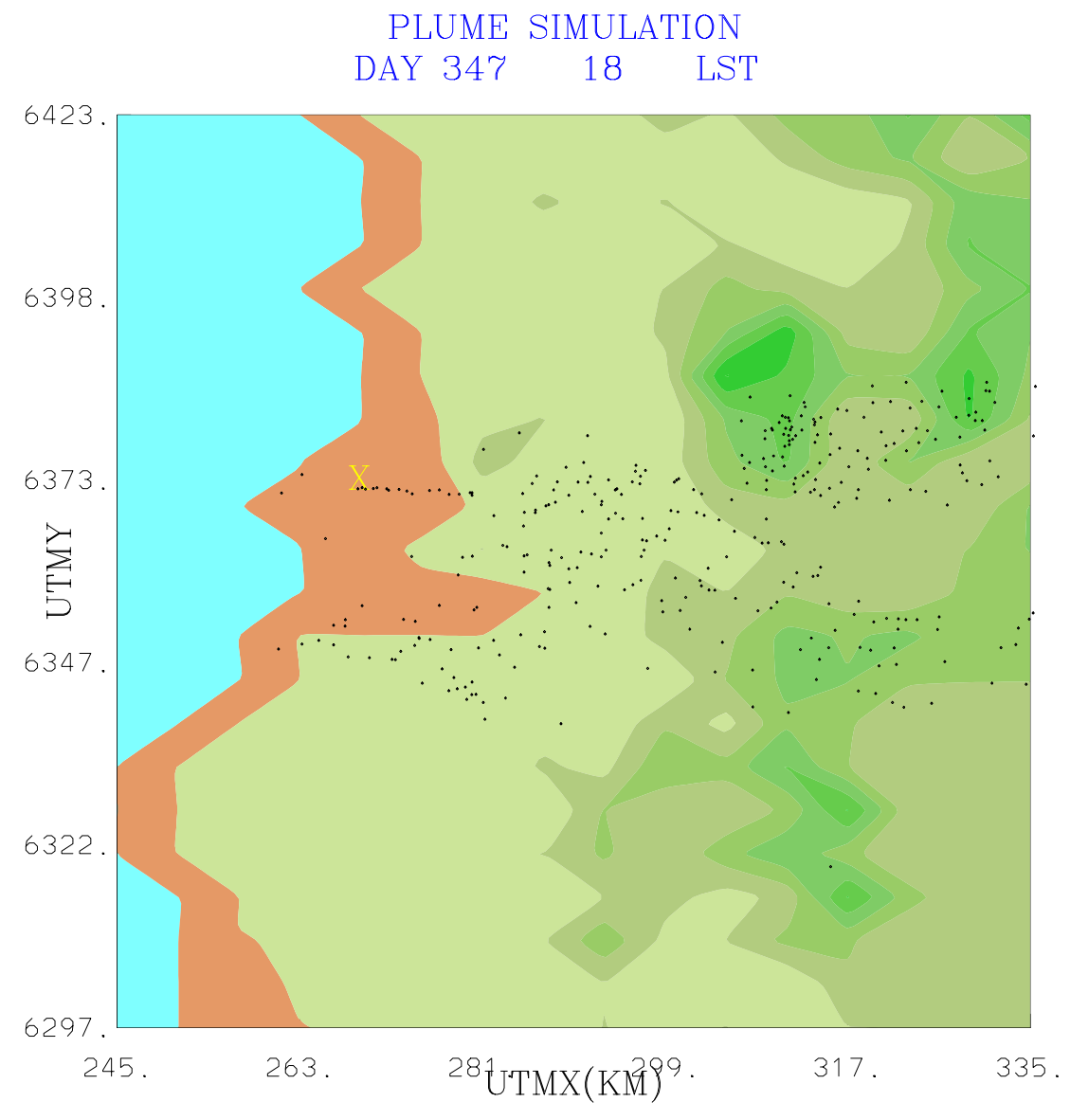

Figure F10. Ventanas plume simulated by the RAPTAD model for prevailing wind direction equal to a) 180 and b) 360 degrees. Current time: 6 pm, Dec. 12. Plume release began at 9 pm, Dec. 11. 